\title{
Numerical Analyses of a Shield Building Subjected to a Large Commercial Aircraft Impact
}

\author{
Jingbo Liu and Pengfei Han (D) \\ Key Laboratory of Civil Engineering Safety and Durability of China Education Ministry, Department of Civil Engineering, \\ Tsinghua University, Beijing 100084, China
}

Correspondence should be addressed to Pengfei Han; feixuehan2003@sina.com

Received 12 September 2017; Revised 2 January 2018; Accepted 4 January 2018; Published 27 February 2018

Academic Editor: Giosuè Boscato

Copyright (C) 2018 Jingbo Liu and Pengfei Han. This is an open access article distributed under the Creative Commons Attribution License, which permits unrestricted use, distribution, and reproduction in any medium, provided the original work is properly cited.

\begin{abstract}
The missile-target interaction method is used to perform simulations of the impact of a commercial B767 aircraft on a shield building made of steel-concrete-steel sandwich panels to study impact damage characteristics. Refined finite element models of a shield building and two large commercial B767 aircraft are developed. The aircraft impact force is given and assessed with the Riera function to verify the B767 aircraft model, and a simulation analysis of tests is performed to verify the concrete model. The peak impact forces of the fuselage, engine, wing, and entire aircraft are approximately linearly proportional to the square of each impact velocity. The shield building subjected to the aircraft impact exhibits no perforation, and the damage range of the shield building expands with increasing impact velocity. The influences of impact velocity, aircraft mass, impact angle, and tie bar diameter on the deformation of the shield building are significant. The thickness of the steel plate plays an important part in the deformation of the shield building, whereas the compressive strength of concrete and the water in circular tank have only a slight effect on the deformation of the shield building.
\end{abstract}

\section{Introduction}

A nuclear power plant (NPP) contains a significant amount of radioactive material; once radiation leaks occur, the consequences are extremely serious. Historically, the Three-Mile Island accident, the Chernobyl accident, and the accident in Fukushima have resulted in serious disasters. An aircraft crashing into a NPP is considered to be extremely hazardous and could cause extensive damage to the NPP. In the 1960s, the U.S. Nuclear Regulatory Commission requested that the safety of the Three-Mile Island NPP station against accidental aircraft impact be evaluated [1]. Subsequently, several plants in Switzerland and Belgium and all NPPs in Germany have been specifically designed to resist aircraft impact. The safety assessment and design basis mentioned above are based on the impact force of a military aircraft or small commercial aircraft. Since the terrorist attacks on September 11th, 2001, the safety of containment structures against large commercial aircraft impacts has drawn significant attention worldwide; the U.S. Nuclear Regulatory Commission's latest regulations required a design specific assessment of the impact of a large commercial aircraft on a new power plant [2]

In the 1960s, Riera [3] proposed a simplified theory model and an equation to calculate the impact force of an aircraft on a rigid wall. The Riera model is simple and practical, but it does not express the distribution of the impact force. Thus, this model is suitable for analysing the global impact effect, but it is difficult to assess the local impact effect, and target deformation is not considered. Hornyik [4], Sugano et al. [5], and Abbas et al. [6] modified the Riera model. Bangash [7] developed a model with lumped masses interconnected by elastoplastic springs; the impact force time-history curves of a Boeing 707-320 and a combat aircraft FB-111 obtained by this model show close agreement to those obtained by the Riera model. However, the improved precondition of the aforementioned follow-up models is based on additional assumptions, and the complex calculations of these models limit their applications.

Experimental studies were performed at University Karlsruhe to study the load-time curves induced by a soft missile 
with a mass and stiffness distribution along its axis similar to those of a commercial aircraft (neglecting the wing geometry and turbines) impacting a rigid target. Load-time curves under different conditions were obtained by changing the mass of the material in the tank, the impact velocity, and the impact angle [8]. Since 2003, experimental studies of deformable projectiles filled with liquid impacting on walls have been conducted at the Technical Research Centre of Finland (VTT). The mass distribution of the projectile was similar to that of a commercial aircraft and the experimental studies provided data for the calibration and verification of numerical models impacting NPPs [9]. Impact tests using 1/7.5-scale models of an F4 fighter jet were performed to clarify the damage phenomena caused by an aircraft crash into steel-concrete-steel (SCS) sandwich panels. The deceleration characteristics during an aircraft collision into SCS panels, the residual aircraft velocities after perforation, and the strains and deformations of the rear-face steel plates of the SCS panels were obtained. These valuable experimental and analytical data are essential to simulate the impact process by a discrete element method (DEM) [10, 11]. Pontiroli et al. [12] conducted an experimental series on reinforced concrete panels subjected to scaled soft projectile impacts. Various damage levels of the panels were obtained, ranging from slight bending to projectile perforation to get more data on aircraft impact problems and then validate numerical models. Sugano et al. [5] conducted an experimental study on a target block subjected to a full-scale F4 fighter jet to determine the impact load-time function during aircraft impact. Lee et al. [13] studied local damage to reinforced concrete (RC) panels subjected to scaled engine of commercial aircraft and Zhang et al. [14] studied impact resistance of ultrahigh performance steel fibre reinforced concrete panels subjected to actual and scaled engines of fighter jet.

Numerical simulations can also be used to study NPP containment subjected to aircraft impacts. Rebora et al. [15] extended a method of analysis of dynamic loading conditions to perform a dynamic nonlinear study on the impact of an airplane on the external shield building of a nuclear power plant. Abbas et al. [16] studied the response of an outer containment for different cracking strains of concrete and different locations of aircraft strike for different aircraft. Saarenheimo et al. [17] conducted numerical studies of VTT tests using the commercial Abaqus code, and Thai and Kim [18] and Heckötter and Vepsä [19] conducted finite element (FE) analyses with the software LS-DYNA and AUTODYN on the VTT tests to improve the simulation of RC structures subjected to aircraft impacts. Mizuno et al. [10, 20] investigated full-scale and scaled aircraft based on an F-16 fighter jet impacted on SCS structures using the DEM. Simulation analysis was carried out by using finite element code LSDYNA to compare the impact resistance performance of steel plate reinforced concrete and reinforced concrete panels [21]. The total impact forces of aircraft were applied on a NPP reactor building to study the floor response spectra and the damage potential of aircraft impact induced vibratory loading. Factors influencing the floor response spectra as the impact area, impact force shape, and impact velocity were pointed out, and the potential for indirect assessment of the equipment capacity was discussed [22]. The loading of aircraft was assigned using the respective impact force time-history curve; the stress and deformation of the containment were discussed, and comparative analyses of the global response and local damage of the containment were proposed [23]. Lawver et al. [24] generated finite element models to predict the response of aircraft impacting into concrete runways and soil surfaces or reinforced concrete, steel lined shelters. They presented details of the difference in results using the simplified loading and explicit aircraft impact modeling as well as crash results into runways and soils. Kostov et al. [25] performed a safety assessment of the A92 reactor shield building for resisting a malevolent impact of a large aircraft. Numerical calculations of the impact force timehistory curve and its distribution were conducted using LSDYNA software to study the ability of the shield building to withstand a Boeing 767-200 crash, and analyses of the effects on the impact results obtained with different fidelity models of large aircraft were proposed [26-28].

NPP safety assessment and design against large commercial aircraft crashes have attracted increasing attention. The damage characteristics of nuclear containment against a large commercial aircraft crash are different from those of a small aircraft crash; studies on nuclear containment against a large commercial aircraft crash must be conducted. As seen from the above research methods, the impact force of aircraft normally impacting the rigid wall can be proposed using simplified theoretical models. Experimental research is available for the impact effect of full-scale or scaled aircraft; these results can be compared with numerical simulation results to enhance the credibility of the numerical simulation of full-scale aircraft impacts. Numerical simulations can be divided into three categories: (1) perform simulations of a scaled aircraft impact test to conduct comparative analyses of numerical simulation results with test results to validate the numerical simulation, thus providing credible support for full-scale aircraft impact analyses; (2) load the impact force time-history curve by the Riera model or the aircraft normally impacting the rigid wall on a containment to study the impact damage effects on structure, and (3) develop numerical models of aircraft and nuclear containment to simulate the impact interaction process. The second numerical simulation has its own restriction; that is, it does not consider the interaction between the aircraft and structure. The load area is difficult to determine, and the damage effects of the impact area are not sufficiently simple to assess, but the third numerical simulation can overcome the aforementioned restriction. Thus, the third numerical simulation is employed to study the impact damage characteristics of a shield building subjected to a large commercial aircraft impact in this paper. First, the refined models of a commercial aircraft and shield building are developed; comparative verification of the total impact force is obtained from an aircraft normally impacting the rigid wall versus from the Riera function. The constitutive models are validated by simulating scaled tests in the existing literature, and the impact force time-history curves of each part of the aircraft are proposed. Finally, the impact responses of the shield building in different impact scenarios are discussed. 
TABLE 1: Mass distribution of a Boeing 767-200ER.

\begin{tabular}{lcccccccc}
\hline Type & Part & Fuselage & Wing & Engine & Empennage & Fuel & Cargo & Total \\
\hline Aircraft A & Mass (ton) & 53.97 & 16.78 & 8.75 & 2.7 & 31.3 & - & 113.5 \\
Aircraft B & Mass (ton) & 53.97 & 16.78 & 8.75 & 2.7 & 73.36 & 23.63 & 179.19 \\
\hline
\end{tabular}

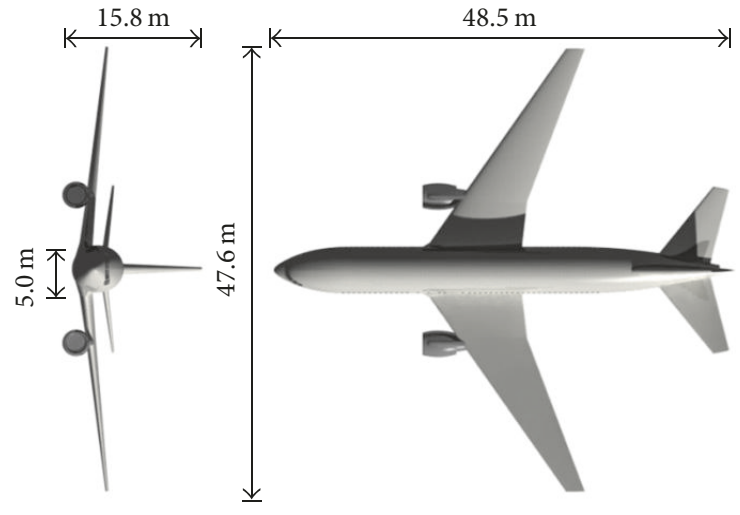

Figure 1: Boeing 767-200ER size.

\section{Numerical Model}

2.1. Aircraft. In general, the selection of commercial aircraft requires accurate representation, including aircraft takeoff weight, aircraft flight hours per year, and aircraft ownership in one region. The Boeing 767-200ER is widely used worldwide and is selected in this impact study as a typical large commercial aircraft. Many related studies have been conducted using this aircraft, and substantial data are available in the literature. One of the two aircraft that impacted the World Trade Center on September 11, 2001, was a Boeing 767-200ER aircraft. The Boeing 767-200ER can accommodate 224 passengers; the maximum takeoff weight is approximately 179 tons. The total length is $48.5 \mathrm{~m}$, the wingspan is $47.6 \mathrm{~m}$, and the fuselage diameter is $5 \mathrm{~m}$, as shown in Figure 1 [27-29].

In this paper, the Boeing 767-200ER is simplified as follows to develop a finite element model (FEM): (a) the geometry is matched to the actual aircraft; (b) the main structures are considered, including aircraft skin, wing ribs, empennage ribs, fuselage frames and strings, and floor beams; the sizes of structures are selected according to actual sizes; and (c) the mass distribution is matched to the actual aircraft, as shown in Table 1; the mass of fuel and cargoes conform with the actual aircraft by adjusting the densities of the wing ribs and aircraft floor. FE models are developed by using Catia, Hypermesh, and LS-DYNA software, in which the floor beams, fuselage frames, and stringers are modeled with beam elements; the other parts of aircraft are modeled with shell elements. The shell elements and beam elements share nodes for displacement compatibility. There are two FE models that are consistent with Boeing 767-200ER, aircraft A and aircraft $B$. The main differences between the two models are that approximately $43 \%$ of the fuel mass is considered in aircraft A except cargo, whereas the total masses of fuel and cargo are considered in aircraft $\mathrm{B}$; the total masses of aircraft A and aircraft B are approximately 113 and 179 tons, respectively.

Liu et al. [27] analysed the mesh size division of an aircraft model and proposed that the axial mesh size had a greater influence on the impact force than the circular mesh size does. The Boeing 767-200ER model is meshed with a global mesh size of approximately $250 \mathrm{~mm}$ according to Liu et al. [27], as shown in Figure 2. The mesh size of regions with complex geometries (e.g., the conjunction between the engine and the wing, and the conjunction between the wing and the fuselage) is refined to ensure the accuracy of the simulation. The numbers of beam elements and shell elements in the aircraft model are approximately 100 thousand and 850 thousand, respectively.

2.2. Shield Building. Currently, international nuclear power construction has entered the third-generation development period. The containment of NPP is composed of an inner steel containment and outer shield building. The main function of the shield building is to keep the internal steel containment and reactor cooling system from damage by external events. A rational simplified model of the shield building is developed by referring to Westinghouse Electric Corporation [30] and the common structure size of an NPP that will be widely adopted in China. The shield building is connected to an auxiliary building, and the cylindrical wall section of the shield building covered by the auxiliary building is a RC structure; a SCS composite structure is used in other parts of the shield building. The SCS portion is constructed with steel surface plates that act as concrete reinforcement. The tie bars are welded to the steel faceplates to develop the composite behaviour of the steel faceplates and concrete. The shear studs are welded to the inside surface of the steel plate. The cylindrical shield wall has an outside radius of $46 \mathrm{~m}$ and a height of $56 \mathrm{~m}$. The circular tank at the top of the shield building has an outside radius of $13 \mathrm{~m}$ and an inside radius of $5 \mathrm{~m}$, and the total height of the shield building is $75 \mathrm{~m}$. A typical shield building and SCS sandwich panel are shown in Figure 3. Solid elements are used to model concrete, whereas shell elements and beam elements are used to model the steel plates and tie bars, and these elements share nodes. Fixed boundary conditions are used for the bottom of the shield building. In the first place, the water in the circular tank is not considered in Section 4.1 and from Sections 4.2.1 to 4.2.3, but the influence of the water in the circular tank to displacement of impact center will be discussed in Section 4.2.4. The model of the shield building is meshed with a global mesh size of approximately $250 \mathrm{~mm}$, and the mesh size of the concrete in air intake is refined. The number of beam elements is approximately 1.42 million, the number of shell elements is about 0.31 million, and the number of solid elements is about 2.19 million. The FE mesh divisions are shown in Figure 4. 

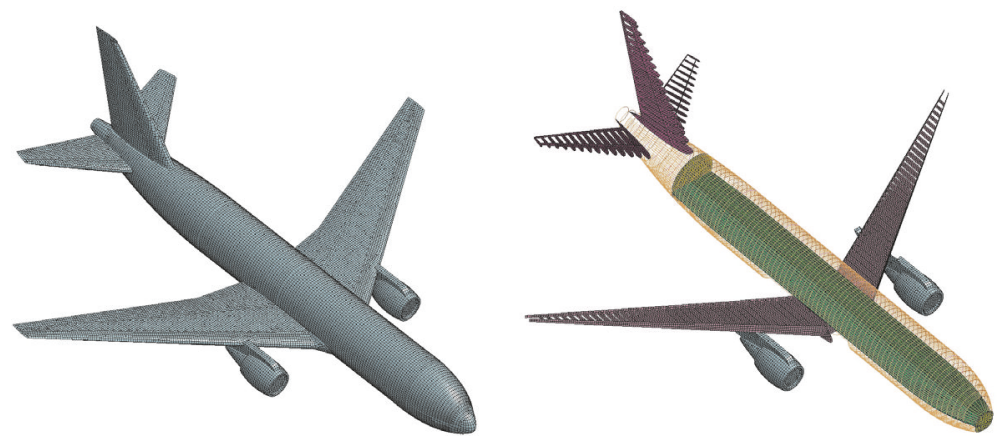

FiguRE 2: Boeing 767-200ER finite element meshing.
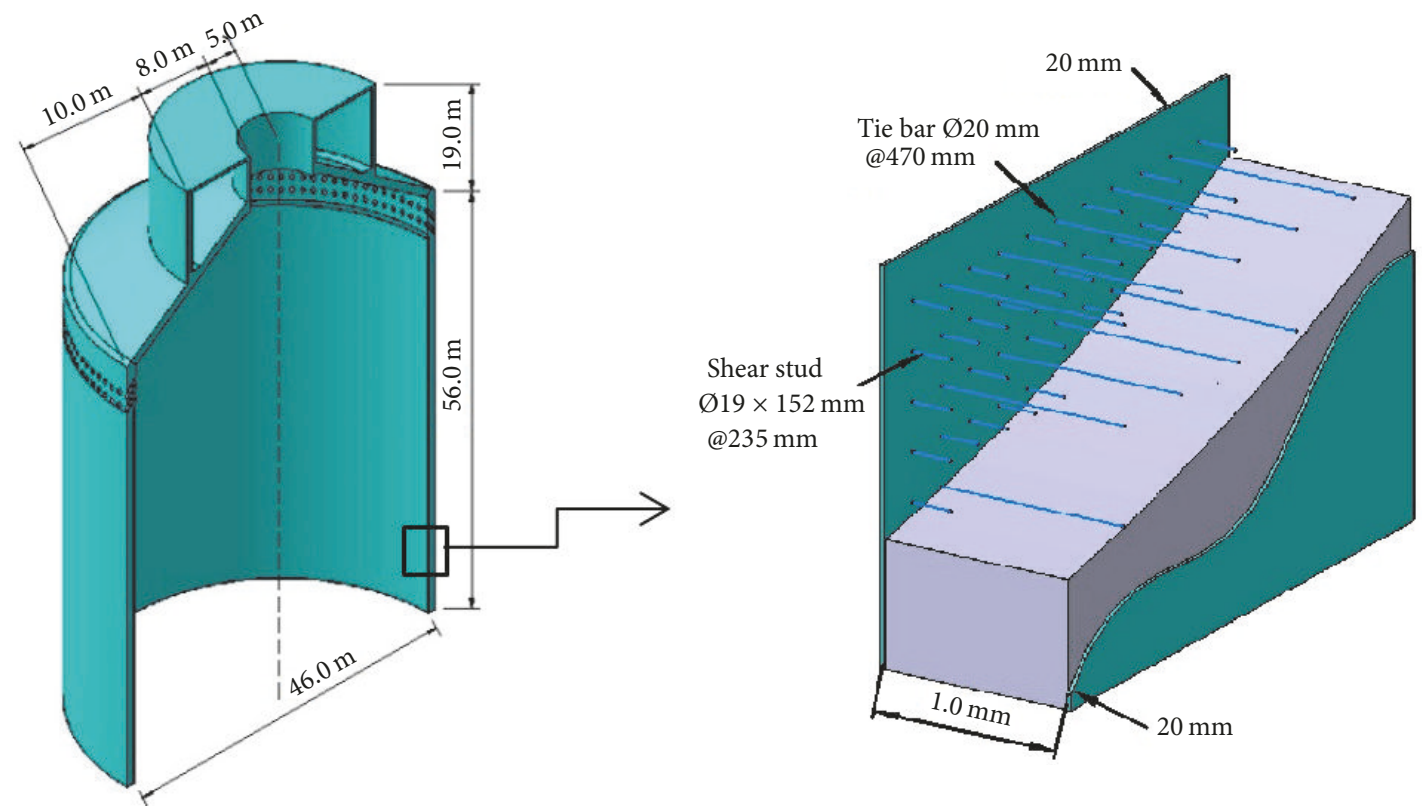

FIGURE 3: Shield building size.

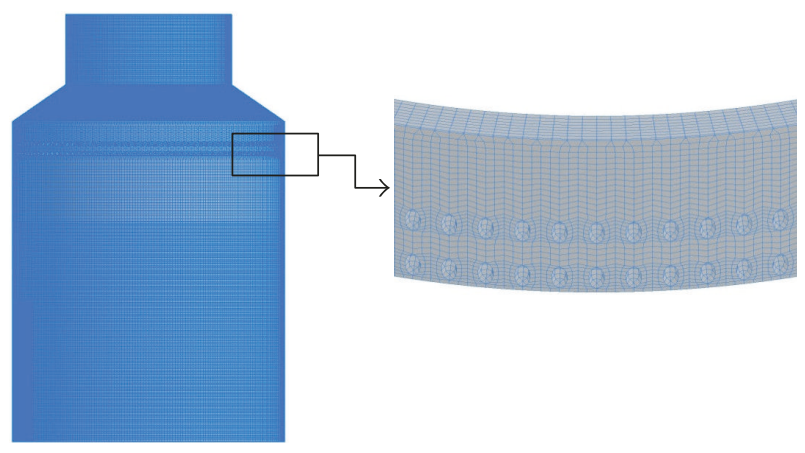

FIGURE 4: Finite element meshing of the shield building.

*CONTACT_AUTOMATIC_NODES_TO_SURFACE is used in the contact between the floor beams, frames, stringers of the aircraft, and the shield building, *CONTACT AUTOMATIC_SURFACE_TO_SURFACE is used in the contact between the other parts of the aircraft and the shield building, and *CONTACT_AUTOMATIC_SINGLE_ SURFACE is, respectively, used in the contacts of the aircraft with itself and the shield building with itself. In the contacts mentioned above, SF (static coefficient of friction) $=0.1$, SFS (scale factor on default slave penalty stiffness) $=1$, SFM (scale factor on default master penalty stiffness) $=1$, and the other contact parameters are program default in LS-DYNA.

\section{Verification of the Numerical Analysis}

\subsection{Verification of the Aircraft Impact Force}

3.1.1. Material Model. The fuselage, wing, and empennage of a Boeing 767-200ER are made of aluminium alloy, and the engine is made of steel. The Johnson-Cook model is used for the impact simulation of shell elements. The equation of the Johnson-Cook model [31] is shown in

$$
\sigma=\left[A+B \varepsilon^{n}\right]\left[1+C \ln \frac{\dot{\varepsilon}}{\dot{\varepsilon}_{o}}\right]\left[1-\left(\frac{T-T_{r}}{T_{m}-T_{r}}\right)^{m}\right],
$$


TABLE 2: MAT015 parameters.

\begin{tabular}{lcccccccccc}
\hline Parameter & $A$ & $B$ & $C$ & $m$ & $n$ & $D_{1}$ & $D_{2}$ & $D_{3}$ & $D_{4}$ & $D_{5}$ \\
\hline Aluminium alloy & 369 & 684 & 0.0083 & 1.7 & 0.73 & 0.13 & 0.13 & -1.5 & 0.011 & 0 \\
Steel & 350 & 275 & 0.022 & 1.0 & 0.36 & 0.05 & 3.44 & -2.12 & 0.002 & 0.61 \\
\hline
\end{tabular}

$A, B, C, n$, and $m$ are the model constants; $D_{1}$ to $D_{5}$ are five model constants.

TABLE 3: MAT03 parameters.

\begin{tabular}{|c|c|c|c|c|c|c|c|c|c|}
\hline Parameter & $\begin{array}{c}\text { Density } \\
\text { (ton } / \mathrm{mm}^{3} \text { ) }\end{array}$ & $\begin{array}{l}\text { Elastic modulus } \\
\qquad(\mathrm{MPa})\end{array}$ & $\begin{array}{c}\text { Shear } \\
\text { modulus } \\
(\mathrm{MPa})\end{array}$ & $\begin{array}{l}\text { Poisson's } \\
\text { ratio }\end{array}$ & $\begin{array}{c}\text { Tangent } \\
\text { modulus (MPa) }\end{array}$ & $\begin{array}{c}\sigma_{y} \\
(\mathrm{MPa})\end{array}$ & $Q$ & $P$ & FS \\
\hline $\begin{array}{l}\text { Aluminium } \\
\text { alloy }\end{array}$ & $2.8 \times 10^{-9}$ & $7.19 \times 10^{4}$ & $2.78 \times 10^{4}$ & 0.33 & 690 & 490 & 6500 & 4 & 0.3 \\
\hline Steel & $7.8 \times 10^{-9}$ & $2.0 \times 10^{5}$ & $7.7 \times 10^{4}$ & 0.3 & 1050 & 400 & 40 & 5 & 0.3 \\
\hline
\end{tabular}

$\sigma_{y}$ is the static yield stress; $Q$ and $P$ are material constants; FS is the values of effective plastic strain for eroding elements.

where $\sigma$ is the equivalent flow stress, $\varepsilon$ is the equivalent plastic strain, $\dot{\varepsilon}$ is the equivalent plastic strain rate, $\dot{\varepsilon}_{o}$ is the reference equivalent plastic strain rate defined by the user (typically defined as $1.0 \mathrm{~s}^{-1}$ or $\left.1 \times 10^{-3} \mathrm{~s}^{-1}\right), T$ is the temperature of the material, $T_{r}$ is the room temperature, and $T_{m}$ is the melting temperature. $A, B, C, n$, and $m$ are the model constants determined by tests. The temperature effect is not considered in this paper; the temperature of the material is equal to the room temperature.

Johnson and Cook [32] proposed a cumulative damage fracture model to express the degradation and failure of material under dynamic loading conditions by determining the strain to fracture as a function of the strain rate, temperature, and pressure. The strain at fracture is given by (2), and the cumulative damage law is defined by (3):

$$
\begin{aligned}
\varepsilon_{f} & =\left[D_{1}+D_{2} \exp \left(D_{3} \frac{\sigma_{m}}{\sigma_{\text {eff }}}\right)\right]\left[1+D_{4} \ln \frac{\dot{\varepsilon}}{\dot{\varepsilon}_{o}}\right] \\
& {\left[1+D_{5}\left(\frac{T-T_{r}}{T_{m}-T_{r}}\right)\right] } \\
D & =\sum_{i=1}^{N} \frac{\Delta \varepsilon_{i}}{\left(\varepsilon_{f}\right)_{i}}
\end{aligned}
$$

where $\varepsilon_{f}$ is the fracture strain, $\sigma_{m}$ is the mean normal stress, $\sigma_{\text {eff }}$ is the effective stress, $D_{1}$ to $D_{5}$ are five model constants, $N$ is the number of items, and $D$ is the failure indicator; failure is assumed to occur when $D=1$, and $\Delta \varepsilon_{i}$ is the effective plastic strain increment, and the calculation parameters are shown in Table $2[28,33]$. Floor beams, fuselage frames, and stringers are modeled with beam elements whose material models use the plastic kinematic model. The strain rate is accounted for using the Cowper-Symonds model [31, 34]. The hardening parameter is equal to zero in this paper; the dynamic yield stress is defined by

$$
\sigma_{\mathrm{yd}}=\sigma_{y}\left(1+\left(\frac{\dot{\varepsilon}}{P}\right)^{1 / Q}\right)
$$

where $\sigma_{\mathrm{yd}}$ is the dynamic yield stress, $\sigma_{y}$ is the static yield stress, and $Q$ and $P$ are material constants. The values of
$Q$ and $P$ are from Jones [34]; the values of effective plastic strain for eroding elements called FS are taken from Liu et al. [27], the values of $\sigma_{y}$ and the tangent modulus are according to Brown Jr. et al. [35] and Zhang et al. [36], and the calculation parameters are shown in Table 3. The aircraft A model impacts the rigid wall at an initial velocity, $V_{i}=200 \mathrm{~m} / \mathrm{s}$, because the aircraft can be nearly destroyed completely at this velocity in some trials to verify the aircraft model; the damage of aircraft $\mathrm{A}$ at different impact moments is shown in Figure 5. The total impact force time-history curve from the FE simulation is shown in Figure 6.

*CONTACT_AUTOMATIC_NODES_TO_SURFACE is used in the contact between the floor beams, frames, stringers of the aircraft, and the rigid wall, $*$ CONTACT $_{\text {- }}$ AUTOMATIC_SURFACE_TO_SURFACE is used in the contact between the other parts of the aircraft and the rigid wall, and $*$ CONTACT_AUTOMATIC_SINGLE_SURFACE is used in the contact of the aircraft with itself. In the contacts mentioned above, SF (static coefficient of friction) $=0.1$, SFS ( scale factor on default slave penalty stiffness) $=1$, SFM (scale factor on default master penalty stiffness) $=1$, and the other contact parameters are program default in LS-DYNA.

3.1.2. Comparison of Impact Forces. Riera [3] proposed a model to calculate the impact force of an aircraft on a rigid wall. The equation is as follows:

$$
F(t)=P_{c}(x(t))+\mu(x(t)) v_{r}^{2},
$$

where $F(t)$ is the total impact force, $P_{c}(x(t))$ is the crushing force located at coordinate $x(t), \mu(x(t))$ is the mass per unit length at location $x(t)$, and $v_{r}$ is the residual velocity of the uncrushed parts of the aircraft.

As shown in (5), the total impact force is the combination of the crushing force and the inertial force against the rigid target. The instantaneous crushing force when the model is used must be determined, but the mean crushing force can be determined more easily than the instantaneous crushing force. The equation of the mean crushing force from Bignon and Riera [37], shown in (6), is used in this paper. 


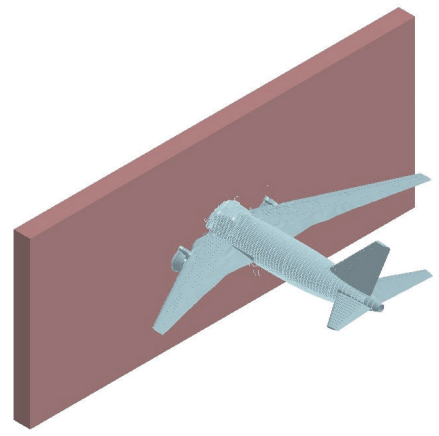

$t=0.1 \mathrm{~s}$

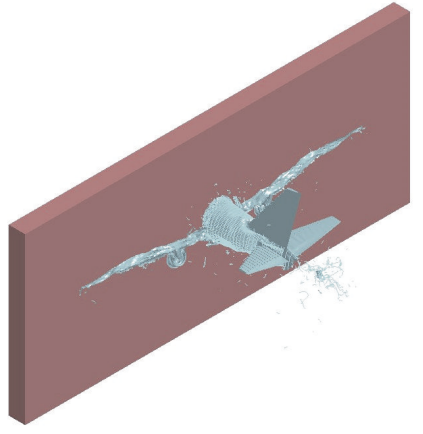

$t=0.2 \mathrm{~s}$

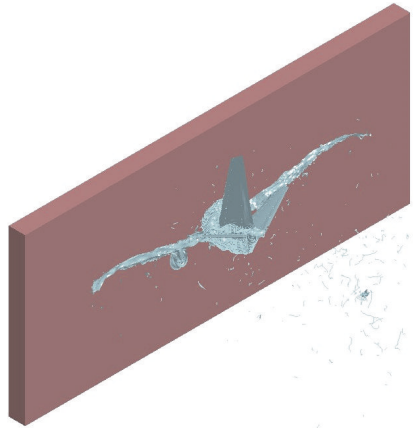

$t=0.3 \mathrm{~s}$

FIgURE 5: Aircraft A impacting the rigid wall target $\left(V_{i}=200 \mathrm{~m} / \mathrm{s}\right)$.

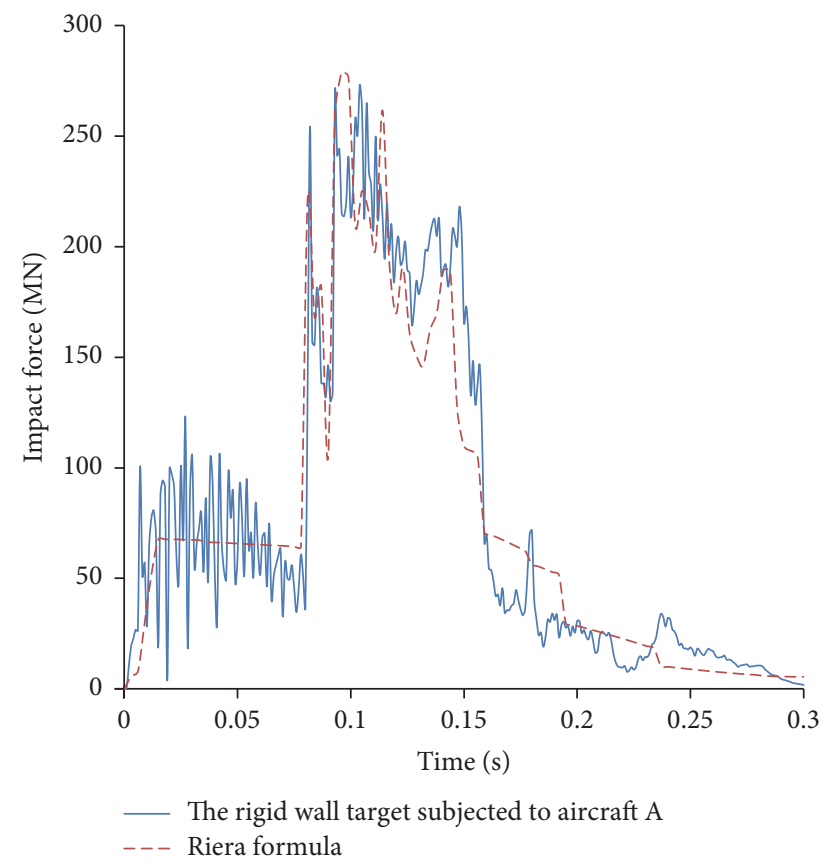

Figure 6: Comparison of the total impact force of aircraft $\mathrm{A}\left(V_{i}=\right.$ $200 \mathrm{~m} / \mathrm{s}$ ).

$$
P_{m}=\left(\frac{\sqrt{3\left(1-\gamma^{2}\right)}}{2 \pi h^{2} E}+\frac{1}{2 \pi R h \sigma_{y}}\right)^{-1}
$$

where $P_{m}$ is the mean crushing force, $h$ is the thickness of the cylindrical shell, $R$ is the mean radius of the cylindrical shell, $E$ is the elastic modulus, $\sigma_{y}$ is the static yield stress, and $\gamma$ is Poisson's ratio.

A comparison of the total impact force calculated by the Riera method with the numerical simulation result is shown in Figure 6. The total impact force duration and peak value calculated by the Riera method are similar to the results of the FE simulation, and the force time-history curve obtained by the Riera method correlates well with the result of the FE simulation. As shown in Figure 7, the total impulse obtained by the Riera method is similar to the result of the

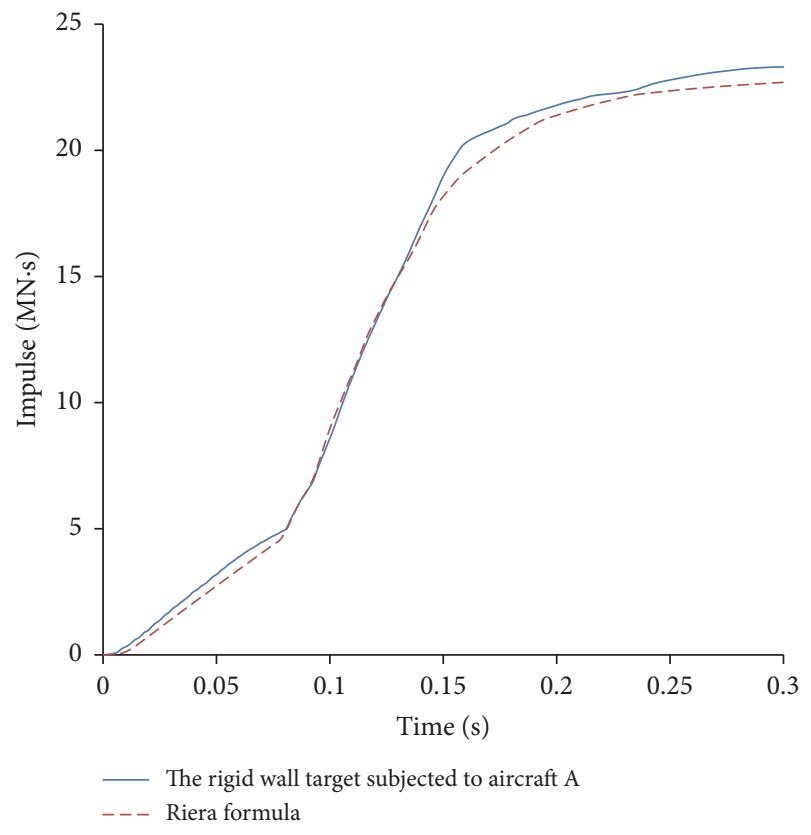

FIgURE 7: Comparison of the total impulse of aircraft $\mathrm{A}\left(V_{i}=\right.$ $200 \mathrm{~m} / \mathrm{s}$ ).

FE simulation. The comparative analysis illustrates that the FE model of the Boeing 767-200ER, the constitutive models that are used, and these parameters are relatively reasonable and that the results of the FE simulation are credible.

3.2. Comparison of Concrete Model Based on Selected Impact Experiments with SCS Sandwich Panels. Details of the experimental study of 1/7.5-scale models of aircraft and different thicknesses of SCS panels were provided in a previous study [10]. Two types of panels were used for the experiments: the full type had steel plates on both faces of the panel, and the half type had a steel plate on the rear-face only, with rebar on the front side. The SCS panels were $1.7 \mathrm{~m}$ squares with panel thicknesses of 60, 80, and $120 \mathrm{~mm}$ (HSC-60, FSC-60, FSC80, HSC-80, and HSC-120). The thicknesses of the steel plate were $0.8 \mathrm{~mm}$ and $1.2 \mathrm{~mm}$. The aircraft model was designed with reference to the damage process of an actual aircraft 
observed in the full-scale aircraft impact test to represent the mass and axial strength distribution along the impact direction of the engine and fuselage. The fuselage consisted of a 2-mm-thick fibreglass cylinder and a high-density, lowstrength foam filler, and the engine consisted of a $0.127-\mathrm{mm}$ thick steel outer shell, a Hexcel honeycomb core, lead tape attached to the outside, and two 1.6-mm thick steel end plates. In the impact tests, the aircraft model with a total weight of $247.6 \mathrm{~N}$ and a length of $1.350 \mathrm{~m}$ was accelerated to an impact velocity of approximately $150 \mathrm{~m} / \mathrm{s}$ and was collided with SCS panels in free flight [10].

The impact scenarios of the full SCS panel subjected to a scaled aircraft model are simulated to verify the material model of concrete because the cylindrical wall of the shield building is a SCS structure in this paper. The full SCS panels are FSC-60 and FSC-80 in the aforementioned impact experiments.

3.2.1. Material Model. LS-DYNA is widely applied in studying structural responses to shock and impact loads among the readily available FE software [31]. There are a variety of concrete constitutive models in this software, such as MAT016, MAT072R3, MAT078, MAT084, MAT096, MAT111, and MAT159. Each of these models has its own advantages and disadvantages; therefore, FE analysts have many choices but can use comparative analysis to select the most appropriate model. Liu and Zheng [26] used three concrete constitutive models, MAT072R3, MAT096, and MAT111, in FE simulations of RC structures subjected to aircraft to perform a comparative analysis of RC panels subjected to a GEJ79 aircraft engine. The analytical results showed better agreement with the experimental results in the case of MAT072R3 than in the cases of MAT096 and MAT111. Sadiq et al. [21] used two concrete constitutive models, MAT084 and MAT159, to simulate scaled aircraft models impacting RC or SCS panels, respectively; the results showed better agreement with experimental results in the case of MAT084 rather than in the case of MAT111. In this paper, the two better concrete constitutive models mentioned above, MAT072R3 and MAT084, are used to simulate tests of SCS panels subjected to scaled aircraft to select a more reasonable concrete constitutive model. MAT072R3 is based on Karagozian \& Case (K\&C) Concrete Model-Release III, which can generate model parameters based on the unconfined compression strength, density, and Poisson's ratio of the concrete. The shear strength enhancement factor versus the effective strain rate is given a curve, which was proposed by Malvar and Ross [38]. MAT084 allows up to three orthogonal crack planes per element and has mainly been applied to obtain the responses of RC structures subjected to impact loadings. Its keyword input is still relatively simple and does not need considerable knowledge of concrete. A maximum strain for concrete is set as the element erosion criteria using $*$ MAT _ADD_EROSION in LS-DYNA [31]. MAT003 is employed for material models of scaled aircraft and steel plates of SCS panels. The material parameters of the scaled aircraft and SCS panels were provided in previous studies [10, 11]. Concrete is modeled with solid elements, whereas the steel plate is modeled with shell elements, and these elements share nodes.

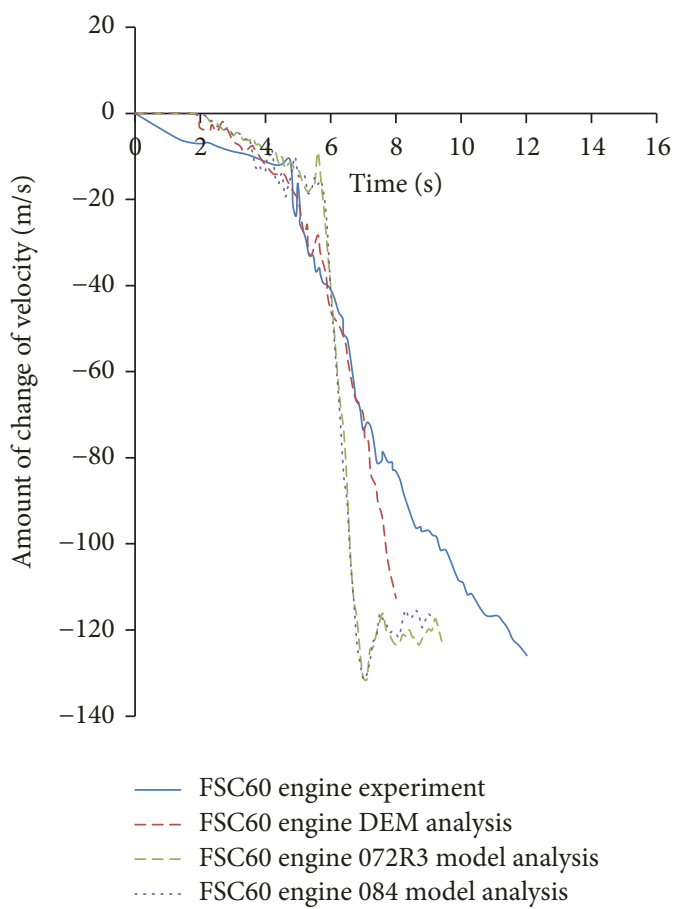

FIGURE 8: Velocity time-history curves of engine impacting FSC-60.

*CONTACT_AUTOMATIC_SURFACE_TO_SURFACE is used in the contact between the scaled aircraft and the SCS panel; *CONTACT_AUTOMATIC_SINGLE_SURFACE is, respectively, used in the contacts of the scaled aircraft with itself and the SCS panel with itself. In the contacts mentioned above, SF (static coefficient of friction) $=0.1$, SFS (scale factor on default slave penalty stiffness) $=1$, SFM (scale factor on default master penalty stiffness) $=1$, and the other contact parameters are program default in LS-DYNA.

3.2.2. Comparison of the Test and Numerical Results. A comparison of the FEM analysis results with both the experimental and analytical results (DEM) $[10,11]$ in terms of the residual velocity and the velocity of scattered debris and the size of crater for two test cases, FSC-60 and FSC-80, is shown in Table 4 . The velocity time-history curves for the engine and fuselage are shown in Figures 8-11. A comparison is made between the curves obtained in the simulation analysis, that is, FEM, and the experimental and DEM results $[10,11]$ of the FSC-60 and FSC-80 panels. The initial velocities for the SCS panels in the simulation analysis are the same as in the experimental study.

In the case of FSC-60, the change in the velocity of the engine until $5 \mathrm{~ms}$ in the FEM results is approximately the same as in the test and DEM results. The residual velocity of the engine after $8 \mathrm{~ms}$ is $30 \mathrm{~m} / \mathrm{s}$ in Mat072R 3 compared to $34 \mathrm{~m} / \mathrm{s}$ in Mat084 and $22 \mathrm{~m} / \mathrm{s}$ in the test after approximately $12 \mathrm{~ms}$ and $40 \mathrm{~m} / \mathrm{s}$ in DEM after approximately $8 \mathrm{~ms}$, as shown in Figure 8 and Table 4 . The residual velocity time-history curve of the fuselage correlates well with the experimental result, as shown in Figure 9 for MAT072R3. The damage area at the front and back surfaces corresponds well with 
TABLE 4: Comparison of the test and numerical results.

\begin{tabular}{|c|c|c|c|c|c|c|}
\hline \multirow{2}{*}{ Case } & \multirow{2}{*}{$\begin{array}{l}\text { Impact velocity } \\
(\mathrm{m} / \mathrm{s})\end{array}$} & \multirow{2}{*}{ Results } & \multirow{2}{*}{$\begin{array}{l}\text { Residual velocity of } \\
\text { engine }(\mathrm{m} / \mathrm{s})\end{array}$} & \multirow{2}{*}{$\begin{array}{l}\text { Velocity of debris of } \\
\text { back face }(\mathrm{m} / \mathrm{s})\end{array}$} & \multicolumn{2}{|c|}{ Size of crater $(\mathrm{mm})$} \\
\hline & & & & & Front face & Back face \\
\hline \multirow{4}{*}{ FSC-60 } & \multirow{4}{*}{152} & Test [11] & 22 & 58 & 340 & 550 \\
\hline & & DEM [11] & 40 & 65 & 410 & 520 \\
\hline & & Mat072R3 & 30 & 68 & 287 & 540 \\
\hline & & Mat084 & 34 & 59 & 280 & 465 \\
\hline \multirow{4}{*}{ FSC-80 } & \multirow{4}{*}{146} & Test [11] & - & - & 450 & - \\
\hline & & DEM [11] & - & - & 430 & - \\
\hline & & Mat072R3 & - & - & 463 & - \\
\hline & & Mat084 & - & - & 398 & - \\
\hline
\end{tabular}

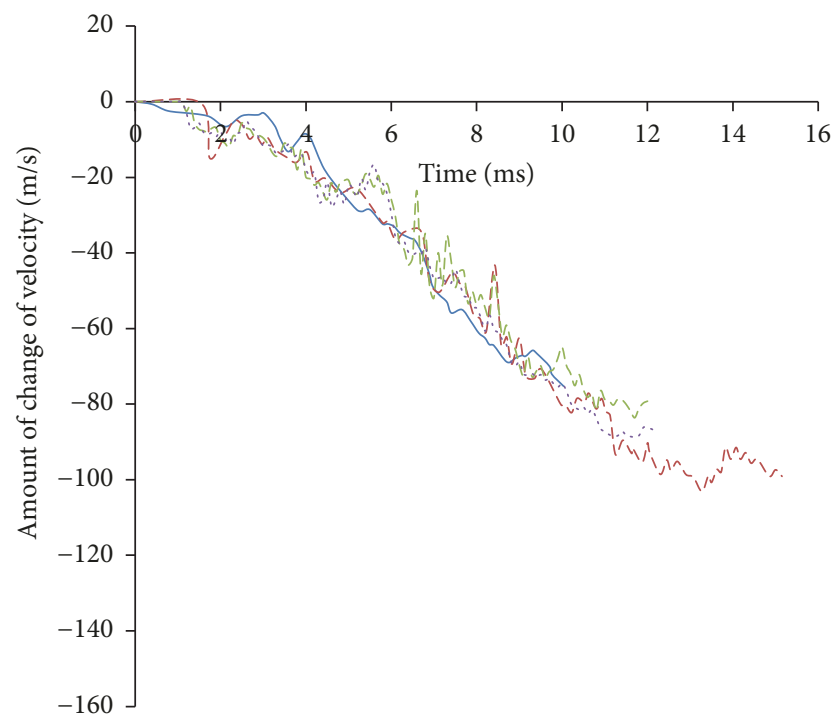

- FSC60 fuselage experiment

- - - FSC60 fuselage DEM analysis

- - - FSC60 fuselage 072R3 model analysis

..... FSC60 fuselage 084 model analysis

FIGURE 9: Velocity time-history curves of fuselage impacting FSC60.

the experimental result in the case of MAT072R3, whereas less damage is observed for MAT084, and the velocity of the debris on the rear-face is $68 \mathrm{~m} / \mathrm{s}$ in the case of MAT072R3, which corresponds closely with $59 \mathrm{~m} / \mathrm{s}$ in the test, as shown in Table 4.

In the case of FSC-80, the crater diameter on the front face of the panel in Mat072R3 is $463 \mathrm{~mm}$, which corresponds closely with the $450 \mathrm{~mm}$ crater size in the test, as shown in Table 4, compared to $234 \mathrm{~mm}$ in Mat084. The residual velocity time-history curves of the engine and fuselage for MAT072R3 and Mat084 correlate well with the experimental result, as shown in Figures 10 and 11. As shown in Figures 12 and 13, the damage results for MAT072R3 and Mat084 to steel plates of both types of panels are approximate to the test results.

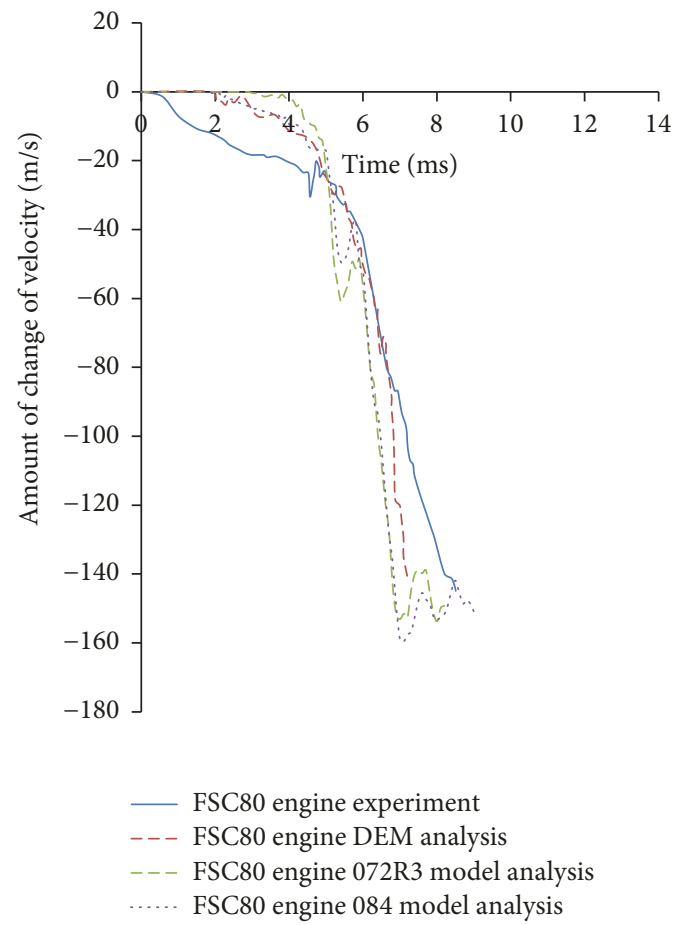

FIGURE 10: Velocity time-history curves of engine impacting FSC80.

The comparison of the results illustrates that the results of MAT072R3 correspond better with experimental and DEM results $[10,11]$ in general; thus, the MAT072R3 model is used for the following parametric analysis in this paper.

\section{Parametric Analysis}

\subsection{Effect of the Associated Aircraft Parameters}

4.1.1. Effect of the Impact Velocity. Five impact velocities$100 \mathrm{~m} / \mathrm{s}, 125 \mathrm{~m} / \mathrm{s}, 150 \mathrm{~m} / \mathrm{s}, 175 \mathrm{~m} / \mathrm{s}$, and $200 \mathrm{~m} / \mathrm{s}$-are selected to simulate an entire aircraft impacting a rigid wall to investigate the influence of the Boeing 767-200ER impact velocity on the impact force. The impact forces of the fuselage, engine, and wing extracted at different aircraft impact velocities are 


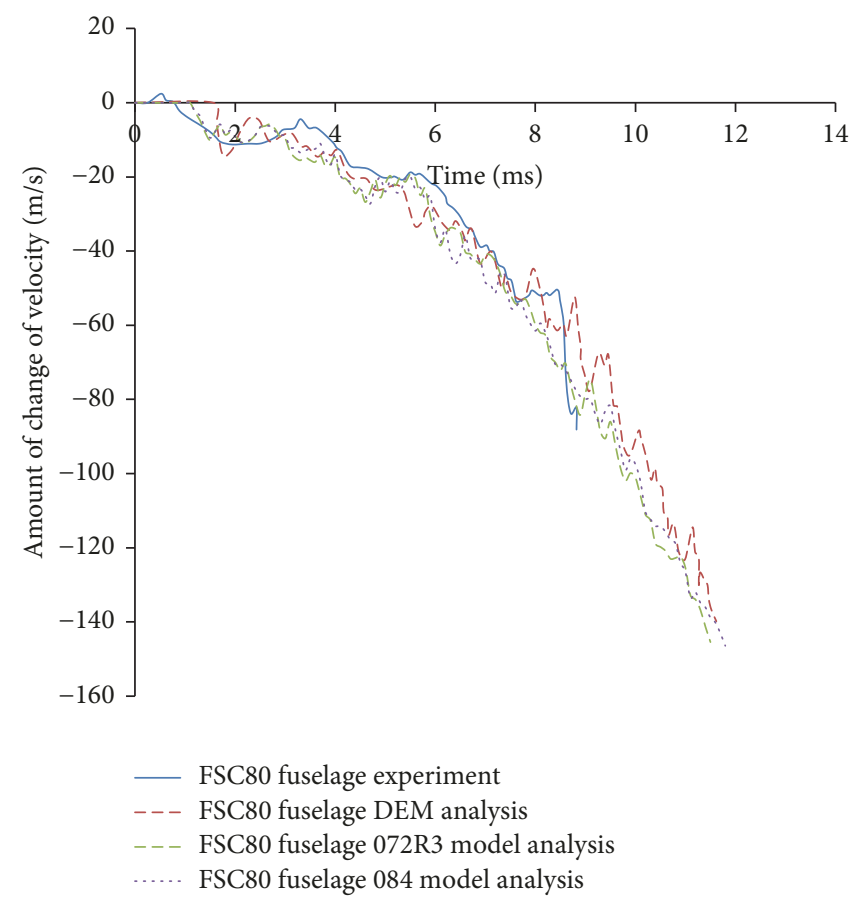

FIGURE 11: Velocity time-history curves of fuselage impacting FSC-80.

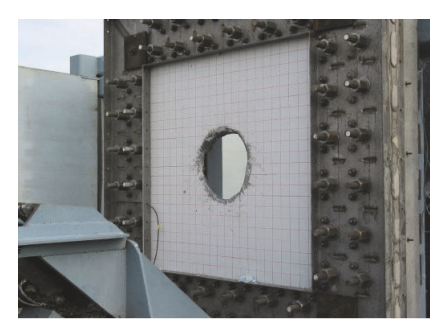

(a) Front face (test) [10]

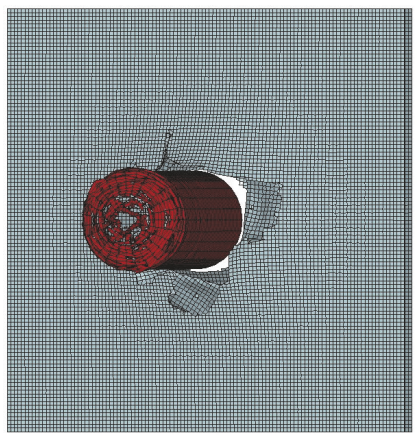

(d) Back face (MAT072R3)

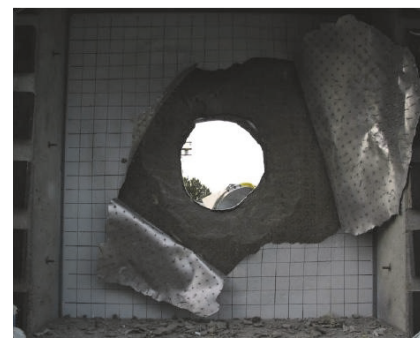

(b) Back face (test) [10]

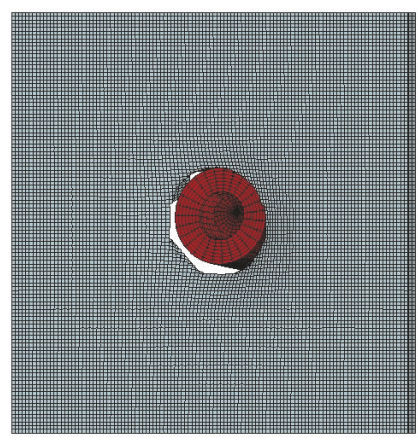

(e) Front face (MAT084)

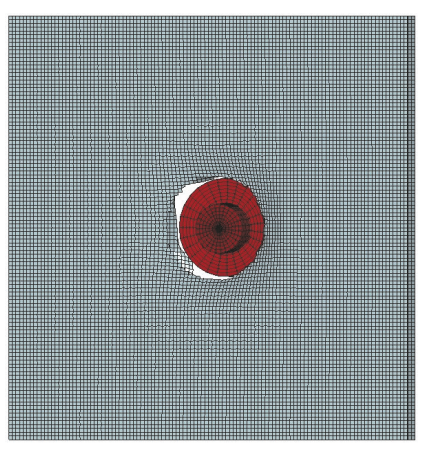

(c) Front face (MAT072R3)

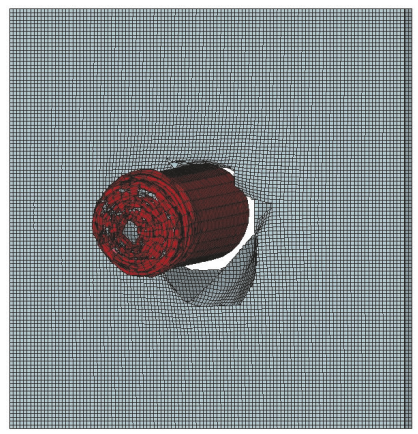

(f) Back face (MAT084)

FIGURE 12: Damage results to steel plates of FSC-60.

compared in Figures 14-16, and the total impact forces at different impact velocities are compared in Figure 17.

As shown in Figure 14, the moment of the peak impact force of the fuselage becomes earlier with increasing impact velocity. There is minimal change in the peak impact forces of the fuselage when the velocities are 100,125 , and $150 \mathrm{~m} / \mathrm{s}$, whereas the alternating amplitude of the peak impact forces of the fuselage changes more significantly when the velocities 


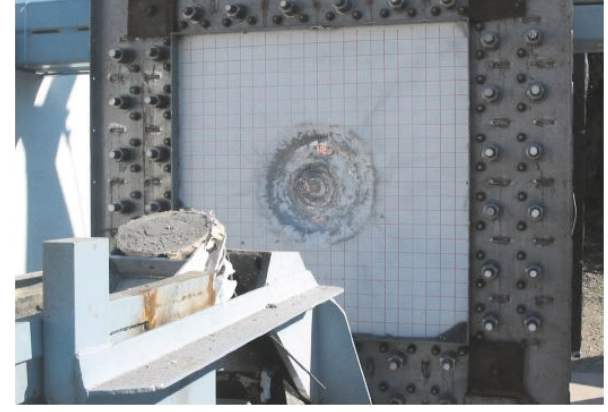

(a) Front face (test) [10]

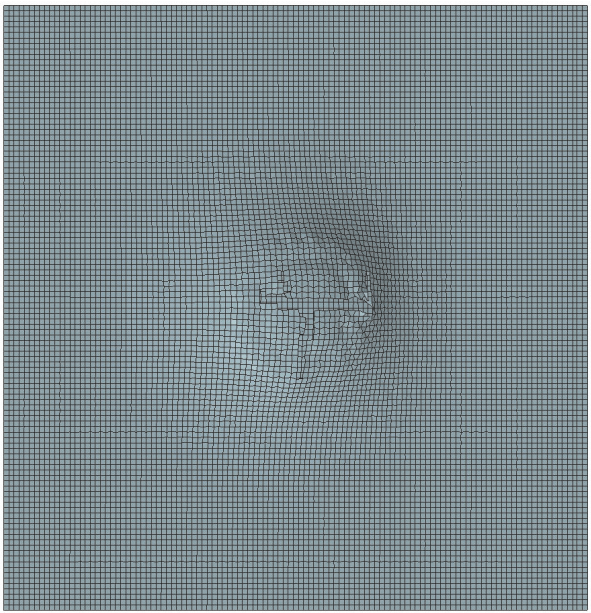

(c) Front face (MAT072R3)

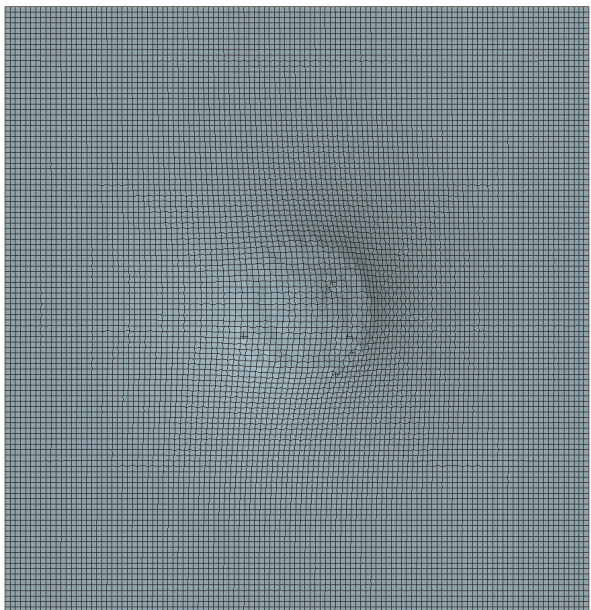

(e) Front face (MAT084)

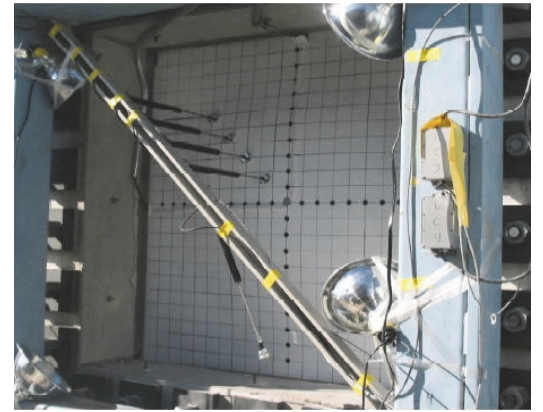

(b) Back face (test) [10]

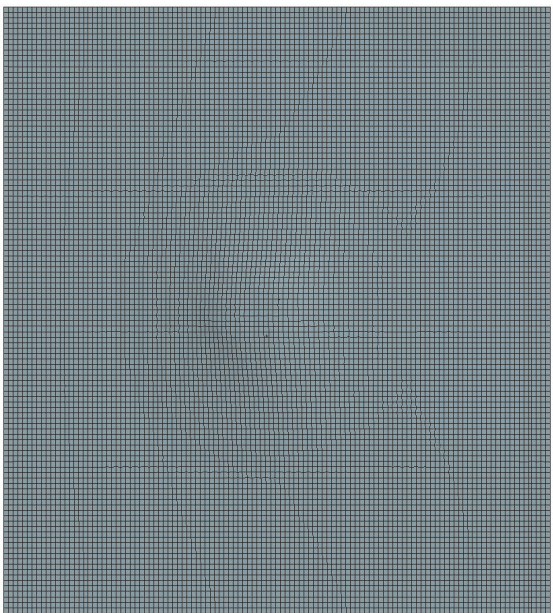

(d) Back face (MAT072R3)

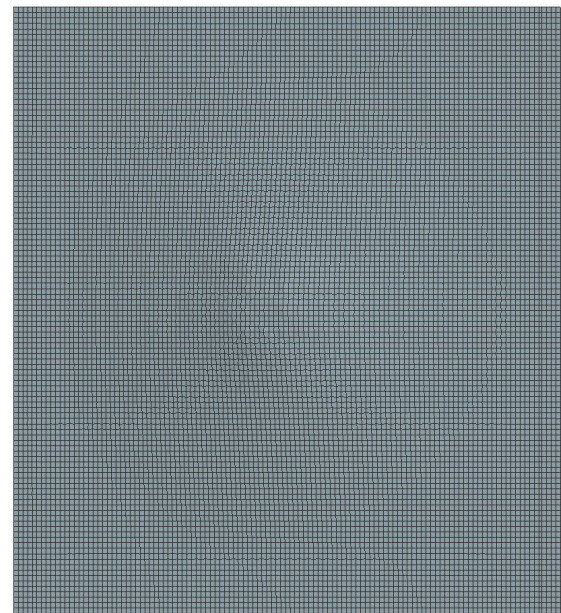

(f) Back face (MAT084)

FIGURE 13: Damage results to steel plates of FSC-80.

are 175 and $200 \mathrm{~m} / \mathrm{s}$. The moment of the peak impact force of the engine comes earlier and the peak value becomes larger with increasing impact velocity, as shown in Figure 15. As shown in Figure 16, the peak impact forces of the wing increase considerably in the case when the impact velocity rises from 125 to $150 \mathrm{~m} / \mathrm{s}$ and in the case when the impact velocity increases from 175 to $200 \mathrm{~m} / \mathrm{s}$, whereas the peak impact forces of the wing change minimally when the impact velocities are 100 and $125 \mathrm{~m} / \mathrm{s}$. The moment of the peak impact force of the wing comes earlier and the pulse width of the impact force becomes smaller with increasing impact velocity. The total impact force can be obtained by making a composition of the impact forces of the fuselage, engine, and wing; the duration of the total impact force reduces but the peak value of the total impact force increases significantly with increasing impact velocity, as shown in Figure 17. 


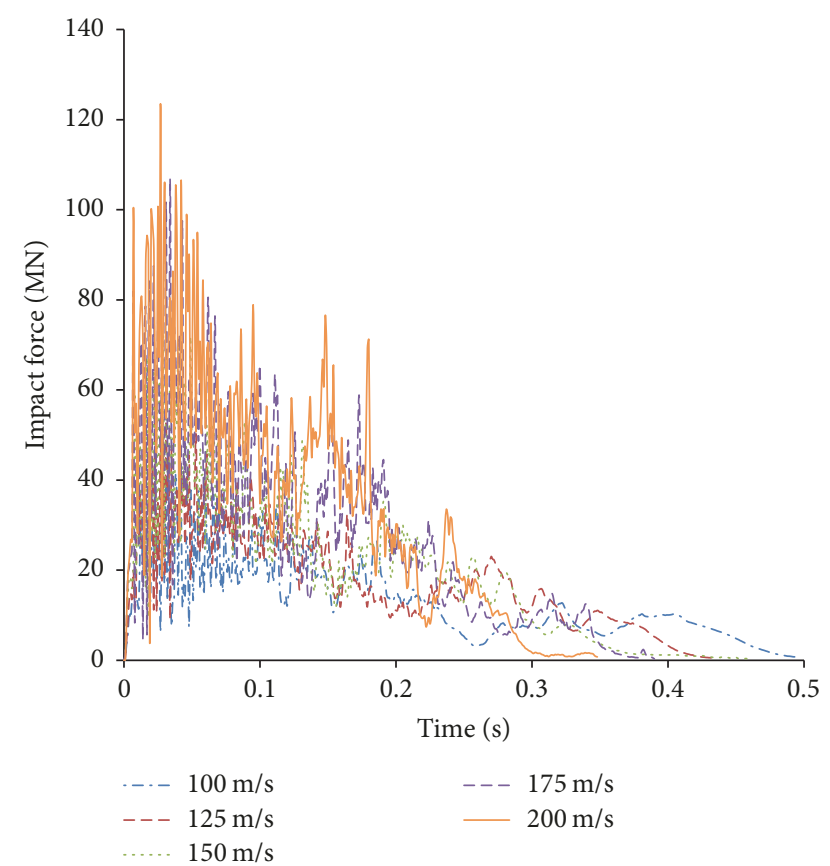

FIGURE 14: Comparison of impact force of fuselage of aircraft A.

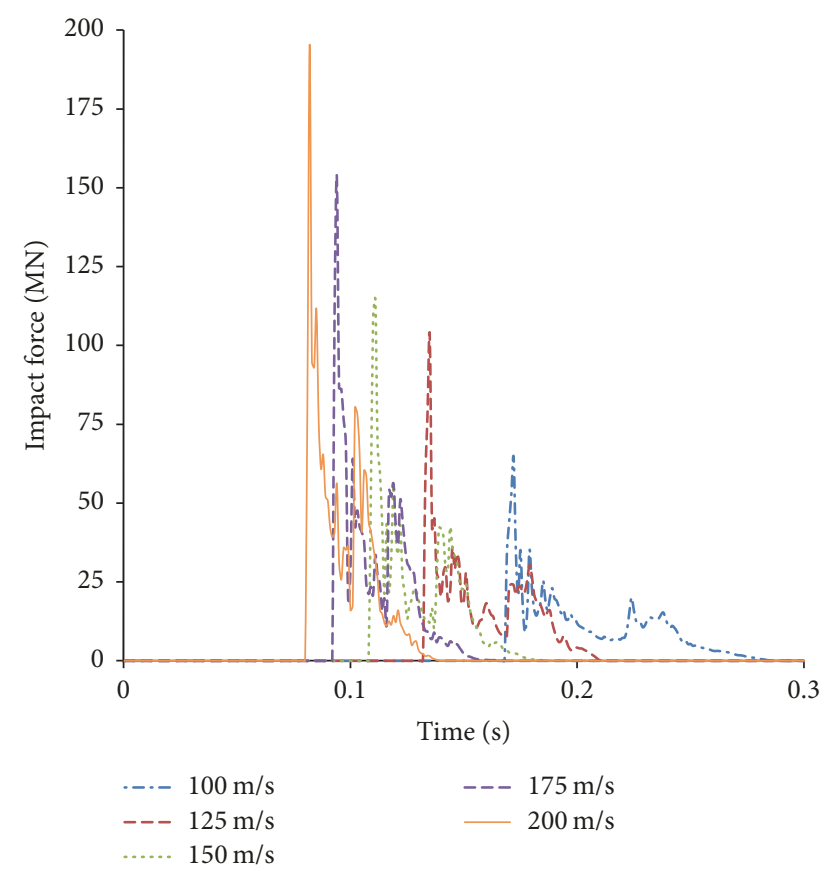

FIGURE 15: Comparison of impact force of two engines of aircraft A.

The total impact force is the combination of the crushing force and the inertial force, which is related to the square of the velocity against the rigid target, according to (5). To illustrate the relationship between the peak impact force of the aircraft and the impact velocity, the peak impact force ratio versus the square of the impact velocity ratio is shown in Figure 18, where $V$ is the impact velocity of a certain part of the aircraft on the rigid wall not equaling the initial velocity

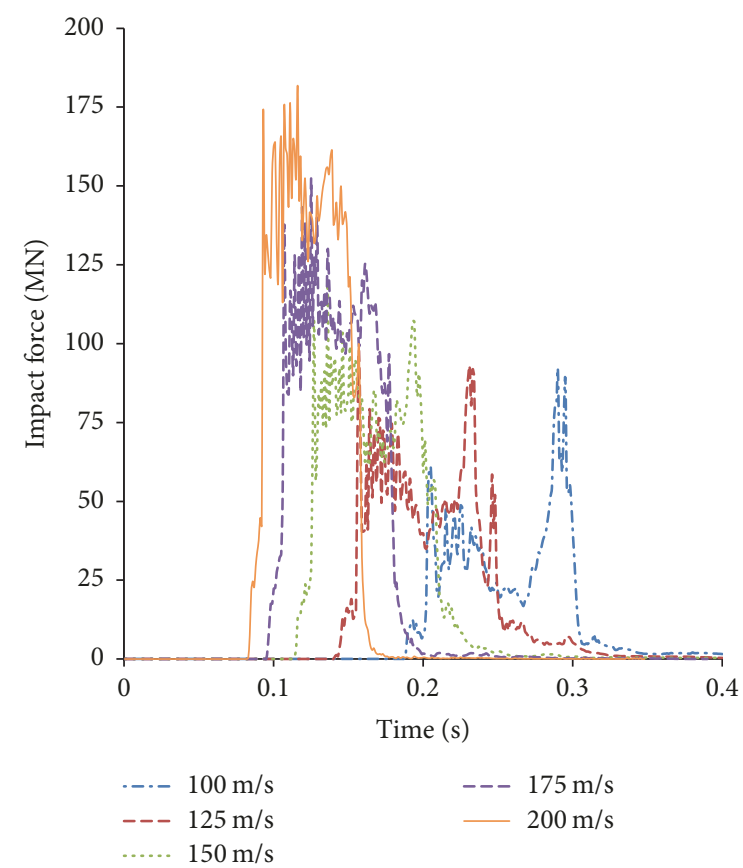

FIGURE 16: Comparison of impact force of wing of aircraft A.

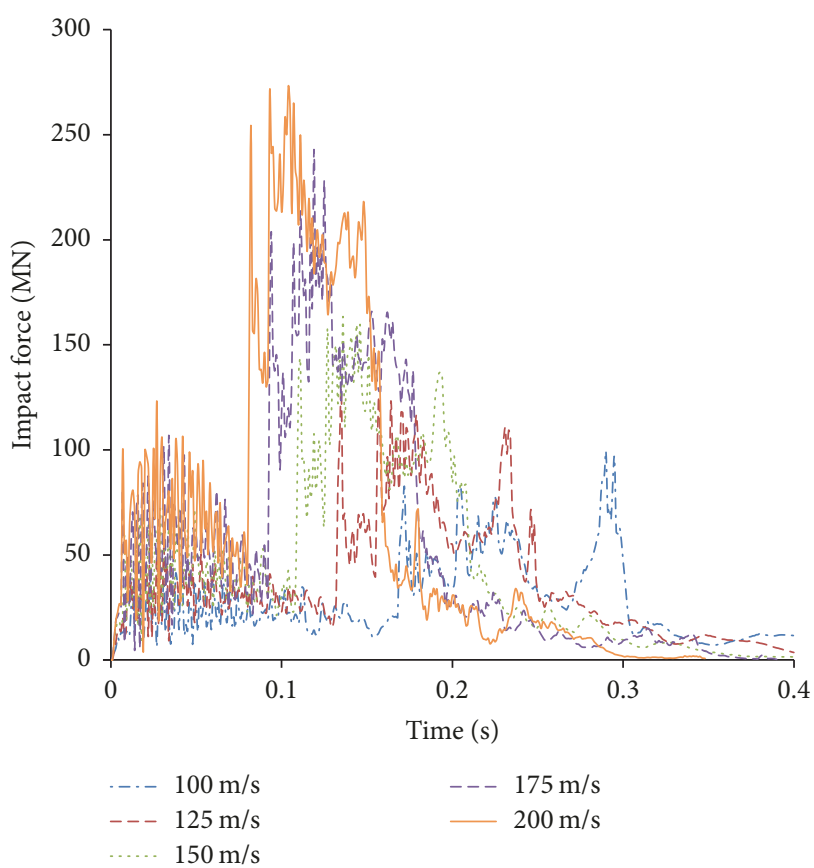

FIGURE 17: Comparison of total impact force of aircraft A.

except the fuselage, because the velocity will reduce with the entire aircraft impact, so $V$ of wing and engine are less than the initial impact velocity of the entire aircraft. $V_{\max }$ is the maximum impact velocity of a certain part of aircraft on the rigid wall, $F$ is the peak impact force of a certain part of the aircraft, and $F_{\max }$ is the maximum of the peak impact forces of a certain part of the aircraft. As shown in Figure 18, the peak impact forces of the fuselage, engine, wing, and entire aircraft 


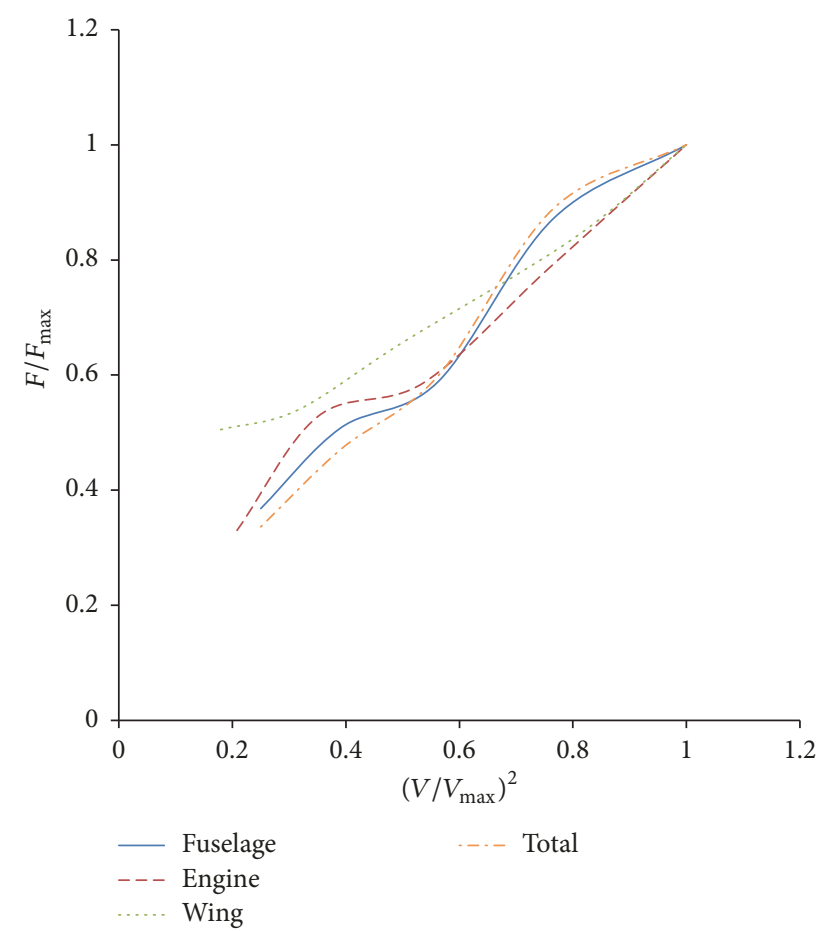

FIGURE 18: The peak impact force ratio versus the square of the impact velocity ratio of aircraft $A$.

are nearly linearly proportional to the square of each impact velocity.

Impact velocities of 100,125 , and $150 \mathrm{~m} / \mathrm{s}$ are considered to study the influences of impact velocity on the impact displacement of the shield building. The FE model of the aircraft is aircraft $A$, the thickness of the plate in the SCS panel of the shield building is $20 \mathrm{~mm}$, the compressive strength of concrete is $46 \mathrm{MPa}$, Poisson's ratio of concrete is 0.2 , the density of concrete is $2.3 \times 10^{3} \mathrm{~kg} / \mathrm{m}^{3}$, and the diameter of the tie bar is $20 \mathrm{~mm}$. There is no perforation in the impact area of the shield building at the three impact velocities mentioned above. The displacement time-history curves of the impact center are shown in Figure 19. The peak impact displacement increases significantly with increasing impact velocity; for instance, the peak impact displacement increases 1.9 times as the impact velocity increases from $100 \mathrm{~m} / \mathrm{s}$ to $150 \mathrm{~m} / \mathrm{s}$. The aircraft impacts the shield building in the case when the impact velocity equals $100 \mathrm{~m} / \mathrm{s}$ at different moments (i.e., $t=0.1,0.2$, and $0.3 \mathrm{~s}$ ), as shown in Figure 20. The characteristics of concrete damage in different impact situations are shown in Figure 21. The damage area increases with increasing impact velocity; the stress concentration appears with considerable plastic damage of concrete in the junction between the RC structure and SCS structure, and a similar phenomenon occurs in the junction between the slope roof and circular tank of the shield building.

4.1.2. Effect of the Impact Angle. The maximum impact force peak will appear when the aircraft impacts the shield building normally; the peak impact force and damage to the shield building will be reduced if the aircraft impacts the shield

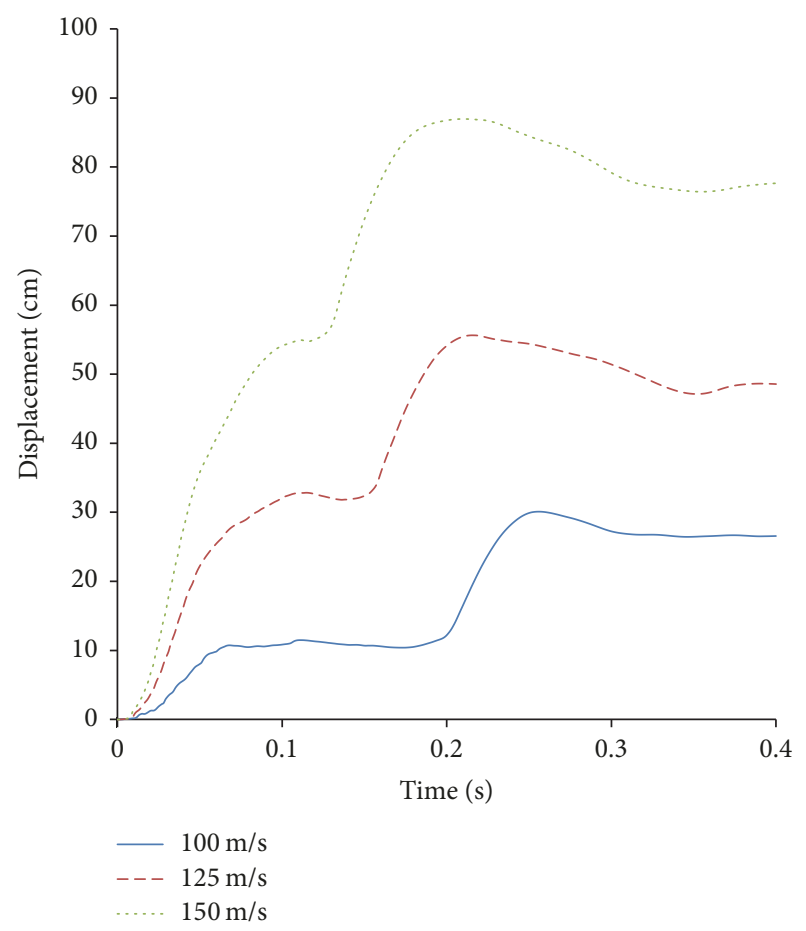

FIGURE 19: Comparison of displacement of impact center at different impact velocities of aircraft $\mathrm{A}$.

building at a certain angle. Thus, the normal impact of the aircraft is typically discussed instead of the impact at other impact angles. However, the damage to the shield building subjected to aircraft impact at a certain angle must be analysed because a normal aircraft impact is rare. The four impact angles, $0^{\circ}, 15^{\circ}, 30^{\circ}$, and $45^{\circ}$, considered for comparative analysis with the other parameters are mentioned in Section 4.1.1 (the thickness of the plate in the SCS panel of the shield building is $20 \mathrm{~mm}$, the compressive strength of concrete is $46 \mathrm{MPa}$, and the diameter of the tie bar is $20 \mathrm{~mm}$ ), and the impact velocity of aircraft A equals $100 \mathrm{~m} / \mathrm{s}$.

The relationship curves of displacement of impact center versus impact angle are shown in Figure 22. The peak displacement decreases considerably with increasing impact angle; there is about $30 \%$ reduction in the peak displacement in the case of the angle increasing from $0^{\circ}$ to $15^{\circ}$, and the peak displacement in the case of $30^{\circ}$ or $45^{\circ}$ is approximately $20 \%$ of that with an impact angle of $0^{\circ}$. The main reason for this change is that the impact energy is related to the square of the impact velocity. A large change in the normal impact velocity will result in a larger displacement change.

4.1.3. Effect of the Aircraft Mass. There are many types of commercial aircraft used worldwide, and the masses of commercial aircraft differ from each other. Even a representative aircraft selected to impact the shield building also has a difference in mass. To study the influence of aircraft mass on impact displacement, two FE models with different masses, aircraft $\mathrm{A}$ and aircraft $\mathrm{B}$, are developed; the mass of aircraft 


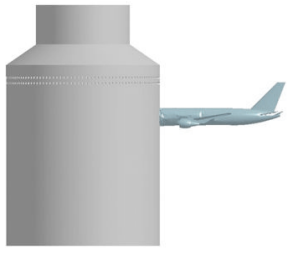

$t=0.1 \mathrm{~s}$

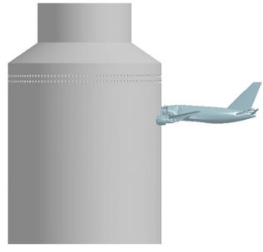

$t=0.2 \mathrm{~s}$

(a) Side view

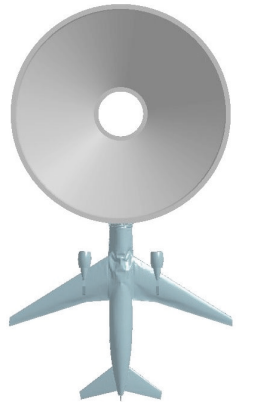

$t=0.1 \mathrm{~s}$

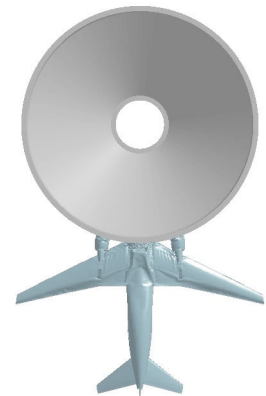

$t=0.2 \mathrm{~s}$

(b) Bottom view

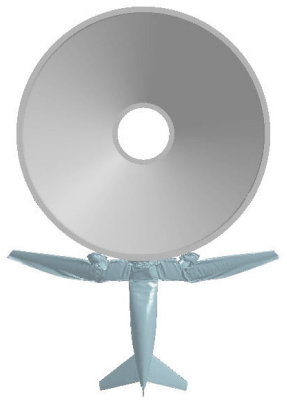

$t=0.3 \mathrm{~s}$

Figure 20: Aircraft A impacts the shield building.

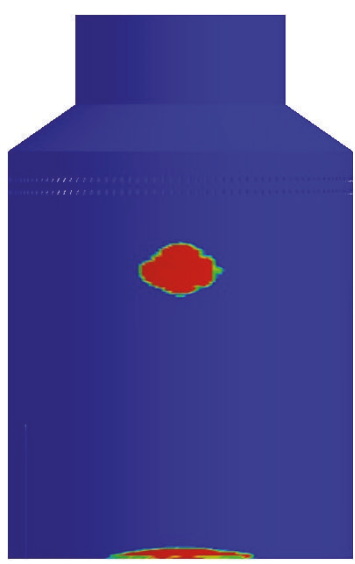

$t=0.15 \mathrm{~s}$

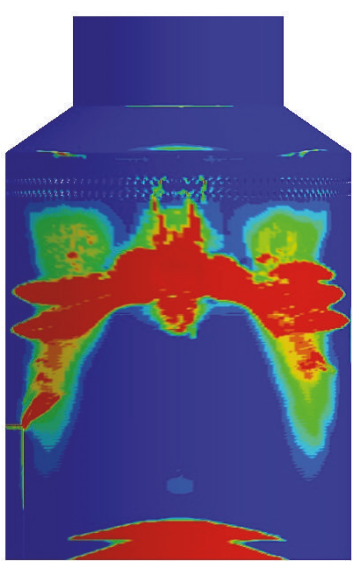

$t=0.3 \mathrm{~s}$

Impact velocity: $100 \mathrm{~m} / \mathrm{s}$

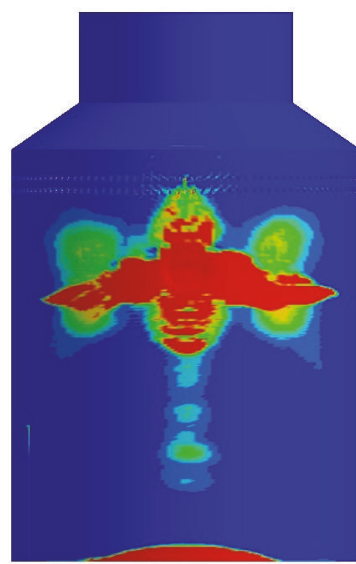

$t=0.15 \mathrm{~s}$

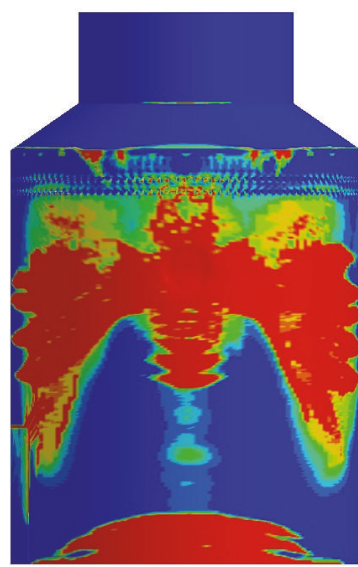

$t=0.3 \mathrm{~s}$

Impact velocity: $125 \mathrm{~m} / \mathrm{s}$

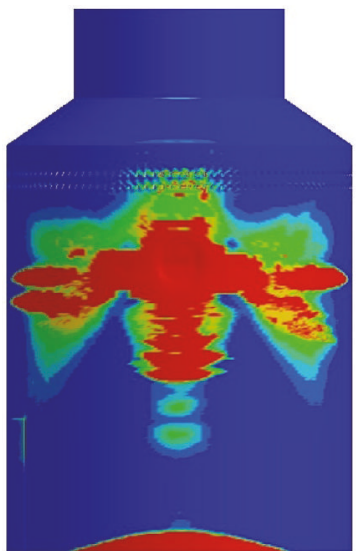

ringe Levels $2.000 e+00$ $1.800 e+00$ $1.600 e+00$ $1.400 e+00$ $1.400 e+00$
$1.200 e+00$
$1.00 e+00$ $1.000 e+00$ $8.000 e-01$ $6.000 e-01$ $4.000 e-01$ $2.000 e-01$ $0.000 e+00$

$t=0.15 \mathrm{~s}$

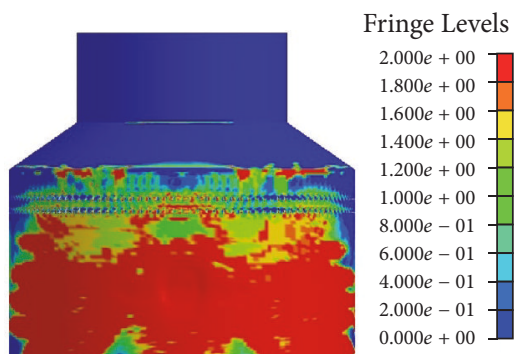

FIGURE 21: Plastic strain of concrete in the outer face of the shield building according to the impact velocity of aircraft A.

A is 113 tons, and the mass of aircraft B is 179 tons. Their impact velocities are both $100 \mathrm{~m} / \mathrm{s}$, the parameters of the shield building are the same as Section 4.1.2.

The displacement time-history curves of the impact center of the shield building subjected to two aircraft are shown in Figure 23. The peak displacement increases from 29 to $65 \mathrm{~cm}$ with increasing aircraft mass. The peak displacement increase by $124 \%$ with a $58 \%$ increase in mass. The simulation results demonstrate the large influence of the aircraft mass on the damage to the shield building. 


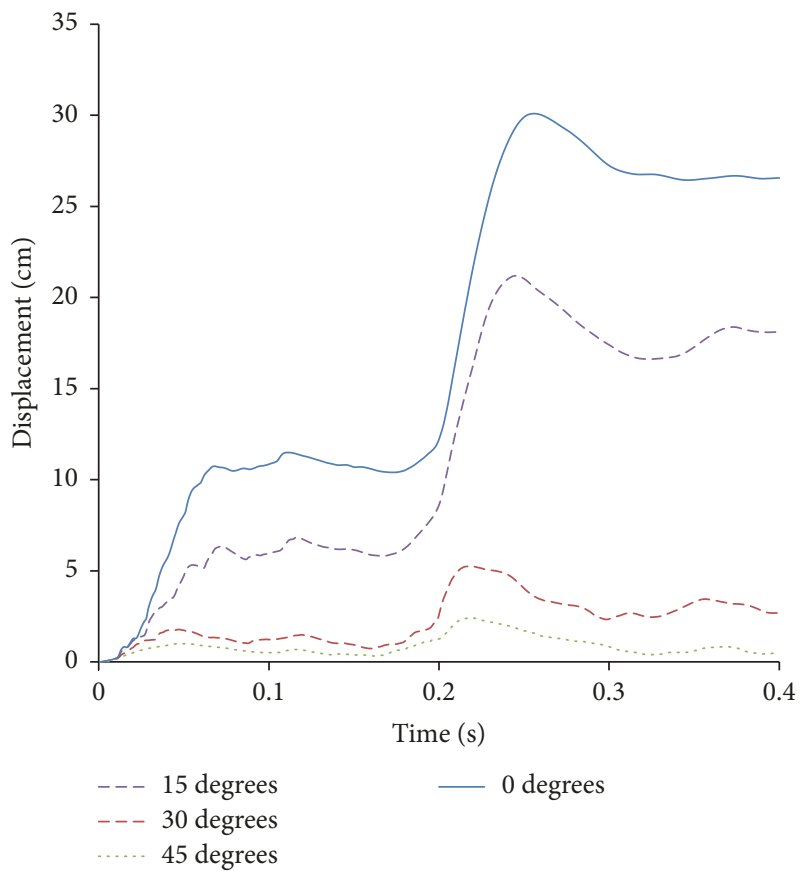

FIGURE 22: Comparison of displacement of impact center at different impact degrees.

4.2. Effect of the Associated Parameters of the Shield Building. The analyses of the aforementioned parameters are based on parameter variations with respect to aircraft. The interaction of the aircraft impacting the shield building must be investigated; the parameters of the aircraft and shield building should be considered. The parameters related to the SCS shield building are considered in this paper, including the tie bar diameter, steel plate thickness, concrete compressive strength, and water in the circular tank. The impact velocity equals $100 \mathrm{~m} / \mathrm{s}$, the aircraft model is aircraft $\mathrm{A}$, the thickness of the plate in the SCS panel of the benchmark shield building is $20 \mathrm{~mm}$, the compressive strength of concrete is $46 \mathrm{MPa}$, and the diameter of the tie bar is $20 \mathrm{~mm}$.

4.2.1. Effect of the Tie Bar Diameter. The SCS structure is an effective composite structure because the tie bars are welded to the steel faceplates to form the interaction with concrete and develop the composite behaviour of the steel faceplates and concrete. Three diameters- $d, 0.75 d$, and $0.5 d$-are considered, where $d$ equals $20 \mathrm{~mm}$, to analyse the effects of the tie bar on the SCS structure and investigate the influences of the tie bar to impact displacement.

The comparison of impact center displacement in cases of different tie bar diameters is shown in Figure 24. The peak impact displacements corresponding to the tie bar diameters of $0.5 d, 0.75 d$, and $d$ are $91.8,54.2$, and $21.2 \mathrm{~cm}$, respectively. As shown in Figure 24, the tie bar diameter greatly influences the impact displacement. The results illustrate that the tie bar diameter is an important factor in engineering design and cannot be removed for a simplified FE model of the shield building. The credibility of the simulation results would decrease if the tie bar were removed from the FE model.

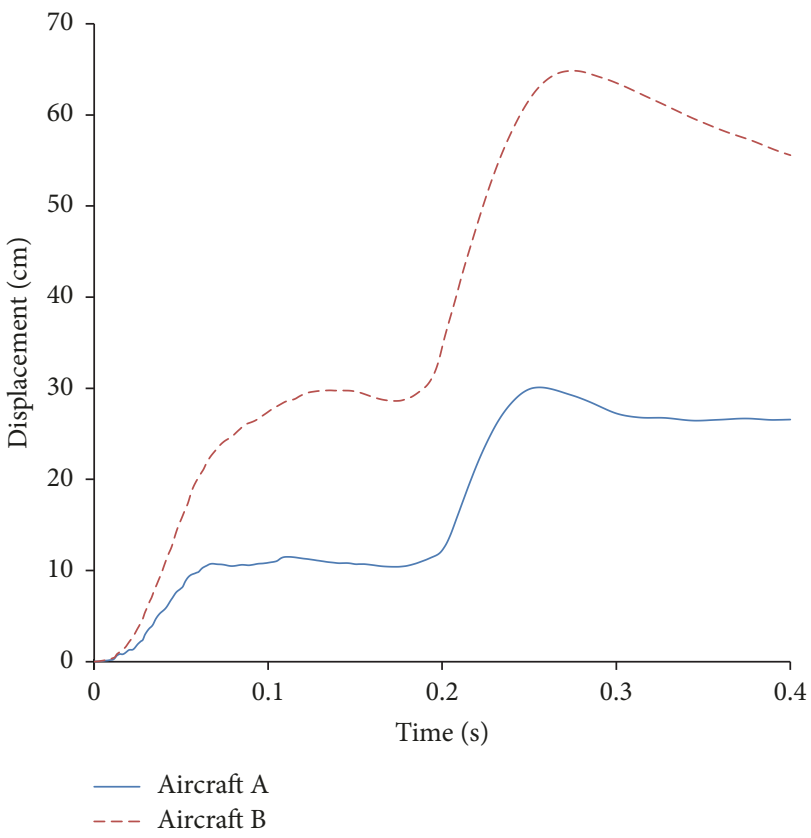

FIGURE 23: Comparison of displacement of impact center in case of different aircraft.

4.2.2. Effect of the Steel Plate Thickness. The influence of steel plate thickness on the impact displacement is shown in Figure 25. Three thicknesses of steel plates are considered-15, 20 , and $25 \mathrm{~mm}$. The peak of the impact displacement decreases with increasing steel plate thickness, as shown in Figure 25; the three impact displacement time-history curves have the same trend. The peak impact displacements corresponding to the steel plate thicknesses of 15,20, and $25 \mathrm{~mm}$ are 35,29 , and $22 \mathrm{~cm}$, respectively. The results show that the steel plate thickness plays an important part in the ability of the SCS structure to withstand an aircraft impact.

4.2.3. Effect of the Concrete Compressive Strength. Three concrete compressive strengths-28, 37, and $46 \mathrm{MPa}$ - are considered to analyse the influence of concrete compressive strength on the ability of the SCS shield building to withstand impact. As shown in Figure 26, the compressive strength of concrete in this structure has a minimal effect on impact displacement; the impact displacement time-history curves have the same trend, and the peak impact displacements are highly similar.

4.2.4. Effect of the Water in the Circular Tank. The studies above on the shield building subjected to aircraft A or aircraft $\mathrm{B}$ did not consider the water in the circular tank at the top of the shield building. But the water in the circular tank of the shield building will vibrate because of impact of aircraft. When a tank containing liquid vibrates, the liquid exerts impulsive and convective hydrodynamic pressure in addition to the hydrostatic pressure; the water can be divided into two parts: the impulsive water moving synchronously along with the tank and the convective water oscillating itself and producing pressures on the walls and the base of the tank 


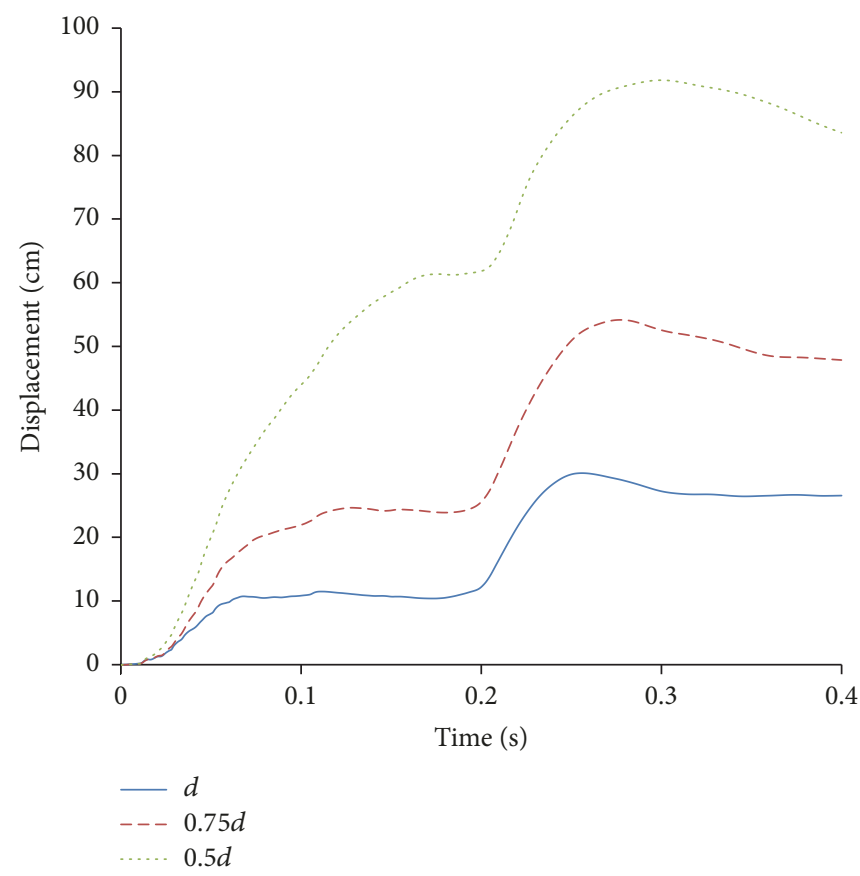

Figure 24: Comparison of displacement of impact center in case of different tie bar diameter.

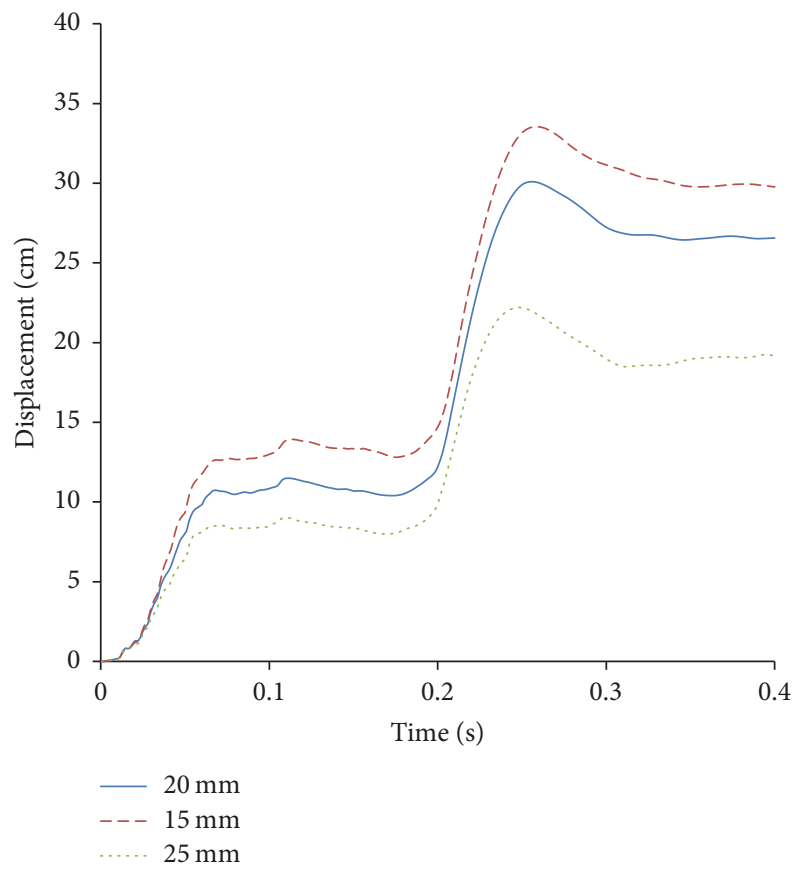

FIGURE 25: Comparison of displacement of impact center in case of different steel plate thickness.

$[39,40]$. After calculation, the first natural frequencies of the water in the circular tank and the shield building are about $0.13 \mathrm{~Hz}$ and $3.1 \mathrm{~Hz}$, respectively, and aircraft impact is a very short progress, so the convective water causes a slight effect on global response of the shield building subjected to a commercial aircraft impact. The equivalent mass of the impulsive water is about $65 \%$ of the total mass of the water

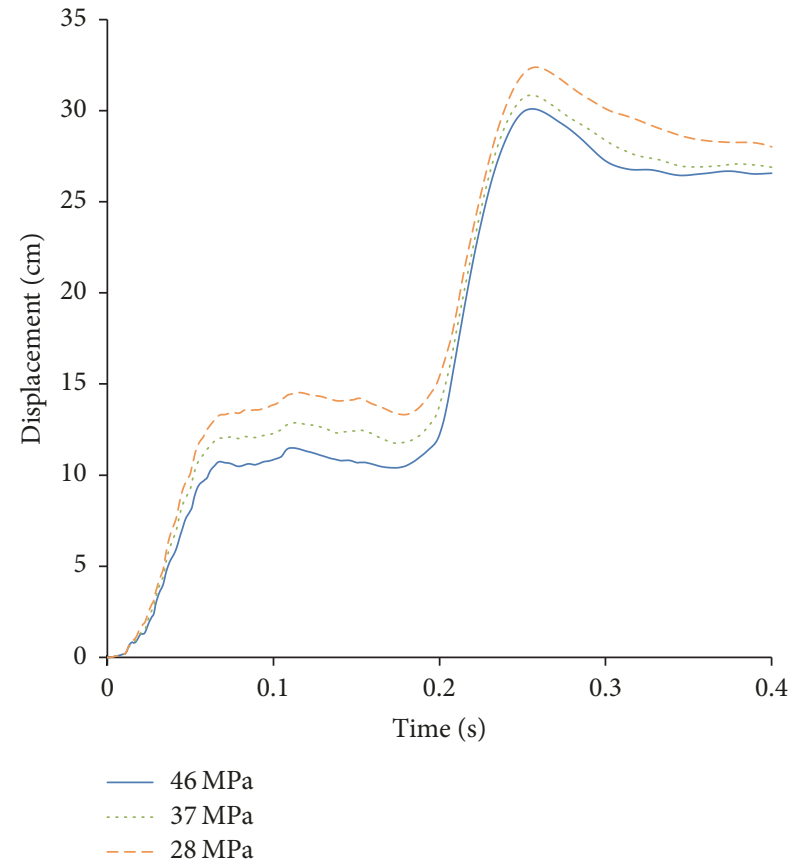

FIGURE 26: Comparison of displacement of impact center in different concrete cases.

in the tank $[39,41]$. In order to perform a comparison of displacement of impact center considering water or not, no water, $65 \%$ water, and $100 \%$ water are considered to discuss. The mass of water in the circular tank is approximately 3000 tons; the mass of water conforms with the actual shield building by adjusting the densities of the concrete of the circular tank. As shown in Figure 27, the water in the 


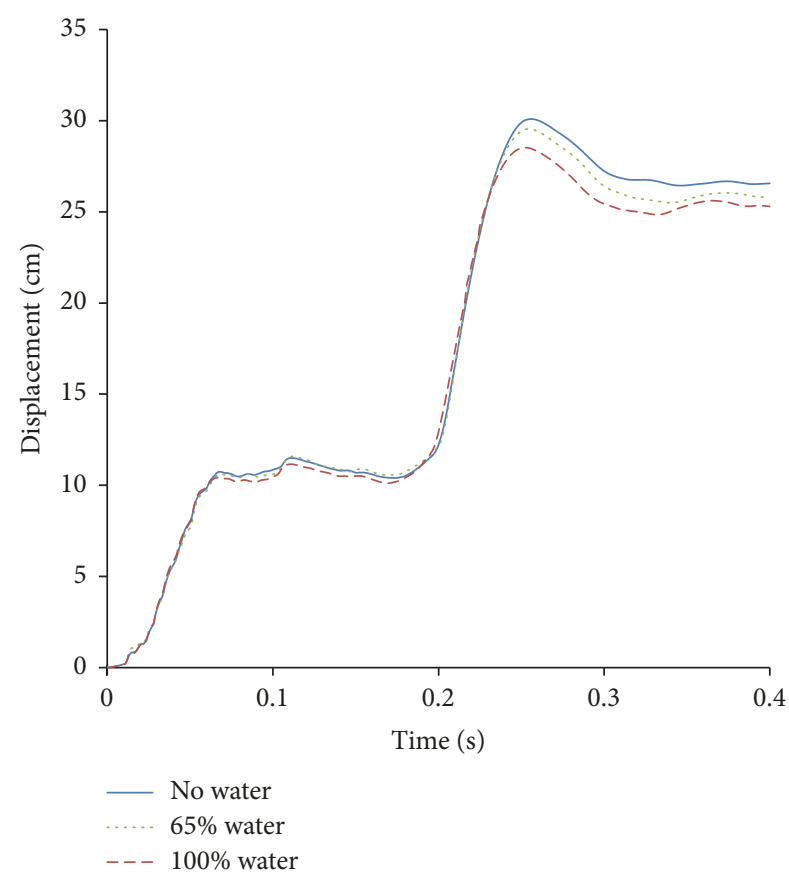

FIGURE 27: Comparison of displacement of impact center considering water or not.

circular tank in this structure has a slight effect on impact displacement; the impact displacement time-history curves have the same trend, and the peak impact displacement of considering $100 \%$ of the total water is about $28.5 \mathrm{~cm}$ and $29.6 \mathrm{~cm}$ for $65 \%$ of the total water and about $30 \mathrm{~cm}$ without water.

\section{Conclusions}

This study developed refined FE models of a shield building and two large commercial B767-200ER aircraft with different masses. The missile-target interaction method was used to perform simulations of a commercial B767-200ER aircraft impacting an SCS shield building. A comparison of the aircraft impact force resulting from an aircraft vertically impacting the rigid wall and an assessment with the Riera function were performed to verify the B767-200ER aircraft model. Then, simulation analyses of SCS panels subjected to scaled aircraft were carried out using FE code LS-DYNA with two constitutive models of concrete to verify and select the more reasonable one. The results in terms of residual velocities, velocity time histories, and crater sizes correlated well with the test and DEM analytical results. The simulation analysis demonstrated that MAT072R3 can simulate the nonlinear response of concrete in the SCS structure in the case of large deformation and a higher strain rate.

Impact force time-history curves of the engine, fuselage, wing, and their resultant impact force time-history curves were proposed by an entire Boeing 767-200ER impacting the rigid wall at different velocities. The peak impact forces of each part and their resultant increase with increasing impact velocity. The peak impact forces of the fuselage, engine, wing, and entire aircraft were approximately linearly proportional to the square of each impact velocity.

A parametric study was performed to investigate the influences of the related parameters on the damage to the shield building subjected to a Boeing 767-200ER. The influences of impact velocity, aircraft mass, impact angle, and tie bar diameter on the deformation of the shield building were significant in the impact scenarios and parametric analyses. The peak impact displacement increased 1.9 times when the impact velocity increased from 100 to $150 \mathrm{~m} / \mathrm{s}$, decreased sharply with increased in the impact angle, and increased approximately 4 times when the tie bar diameter increased from $0.5 d$ to $d$. The peak impact displacement increased approximately 1.2 times when the aircraft mass increased from 113 to 179 tons. The steel plate thickness played an important part in the deformation of the shield building, and the maximum change in the peak displacement resulting from the variation of this parameter was generally controlled within 50\%. However, the compressive strength of concrete and the water in circular tank had only a slight effect on deformation of the shield building. The damage range of the shield building expanded with increasing impact velocity; there was no perforation of the shield building subjected to the aircraft impact in the aforementioned impact scenarios.

\section{Conflicts of Interest}

The authors declare that they have no conflicts of interest regarding the publication of this paper.

\section{Acknowledgments}

This study was supported by the National Science and Technology Major Project of China (Grant no. 2011ZX0600210).

\section{References}

[1] J. D. Riera, "A critical reappraisal of nuclear power plant safety against accidental aircraft impact," Nuclear Engineering and Design, vol. 57, no. 1, pp. 193-206, 1980.

[2] U. S. Nuclear Regulatory Commission, "Aircraft impact assessment," 10 CFR 50.150, 2009.

[3] J. D. Riera, "On the stress analysis of structures subjected to aircraft impact forces," Nuclear Engineering and Design, vol. 8, no. 4, pp. 415-426, 1968.

[4] K. Hornyik, "Analytic modeling of the impact of soft missiles on protective walls," in Proceedings of 4th International Conference on Structural Mechanics in Reactor Technology, pp. 1-12, California, Calif, USA, 1977.

[5] T. Sugano, H. Tsubota, Y. Kasai et al., "Full-scale aircraft impact test for evaluation of impact force," Nuclear Engineering and Design, vol. 140, no. 3, pp. 373-385, 1993.

[6] H. Abbas, D. K. Paul, P. N. Godbole, and G. C. Nayak, "Reactiontime response of aircraft crash," Computers \& Structures, vol. 55, no. 5, pp. 809-817, 1995.

[7] M. Y. H. Bangash, Shock, Impact and Explosion: Structural Analysis and Design, Spring Press, Berlin, Germany, 2009.

[8] D. Ruch, N. Herrmann, and H. S. Muller, "Evaluation of loadtime functions due to impact of soft missiles," in Proceedings of 
17th International Conference on Nuclear Engineering, Brussels, Belgium, July 2009.

[9] A. Lastunen, I. Hakola, E. Järvinen, K. Calonius, and J. Hyvärinen, "Impact Test Facility," in Proceedings of 19th International Conference on Structural Mechanics in Reactor Technology, pp. 1-8, Toronto, Canada, 2007.

[10] J. Mizuno, N. Koshika, Y. Sawamoto, N. Niwa, T. Yamashita, and A. Suzuki, "Investigation on impact resistance of steel plate reinforced concrete barriers against aircraft impact partl: test program and results," in Proceedings of the in proceedings of 18th International Conference on Structural Mechanics in Reactor Technology, pp. 2566-2579, Beijing, China, 2005.

[11] J. Mizuno, N. Koshika, H. Morikawa, K. Wakimoto, K. Kobayashi, and R. Fukuda, "Investigation on impact resistance of steel plate reinforced concrete barriers against aircraft impact Part 2: simulation analyses of scale model impact tests," in Proceedings of the in proceedings of 18th International Conference on Structural Mechanics in Reactor Technology, p. pp, Beijing, 2580-2590, China, 2005.

[12] C. Pontiroli, A. Rouquand, L. Daudeville, and J. Baroth, "Soft projectile impacts analysis on thin reinforced concrete slabs: Tests, modelling and simulations," European Journal of Environmental and Civil Engineering, vol. 16, no. 9, pp. 1058-1073, 2012.

[13] S. Lee, S.-S. Cho, J.-E. Jeon, K.-Y. Kim, and K.-S. Seo, "Impact analyses and tests of concrete overpacks of spent nuclear fuel storage casks," Nuclear Engineering and Technology, vol. 46, no. 1, pp. 73-80, 2014.

[14] T. Zhang, H. Wu, Q. Fang, T. Huang, Z. M. Gong, and Y. Peng, "UHP-SFRC panels subjected to aircraft engine impact: Experiment and numerical simulation," International Journal of Impact Engineering, vol. 109, pp. 276-292, 2017.

[15] B. Rebora, T. Zimmermann, and J. P. Wolf, "Dynamic rupture analysis of reinforced concrete shells," Nuclear Engineering and Design, vol. 37, no. 2, pp. 269-297, 1976.

[16] H. Abbas, D. K. Paul, P. N. Godbole, and G. C. Nayak, "Aircraft crash upon outer containment of nuclear power plant," Nuclear Engineering and Design, vol. 160, no. 1-2, pp. 13-50, 1996.

[17] A. Saarenheimo, K. Calonius, M. Tuomala, and I. Hakola, "Soft Missile Impact on Shear Reinforced Concrete Wall," Journal of Disaster Research, vol. 5, no. 4, pp. 426-436, 2010.

[18] D.-K. Thai and S.-E. Kim, "Failure analysis of reinforced concrete walls under impact loading using the finite element approach," Engineering Failure Analysis, vol. 45, pp. 252-277, 2014.

[19] C. Heckötter and A. Vepsä, "Experimental investigation and numerical analyses of reinforced concrete structures subjected to external missile impact," Progress in Nuclear Energy, vol. 84, article no. 2054, pp. 56-67, 2015.

[20] J. Mizuno, N. Koshika, E. Tanaka, A. Suzuki, I. Nishimura, and Y. Mihara, "Investigation on impact resistance of steel plate reinforced concrete barriers against aircraft impact Part 3: analyses of full-scale aircraft impact," in Proceedings of the in proceedings of 18th International Conference on Structural Mechanics in Reactor Technology, pp. 2591-2603, Beijing, China, 2005.

[21] M. Sadiq, X. Y. Zhu, and R. Pan, "Simulation analysis of impact tests of steel plate reinforced concrete and reinforced concrete slabs against aircraft impact and its validation with experimental results," Nuclear Engineering and Design, vol. 273, pp. 653-667, 2014.

[22] A. Andonov, K. Apostolov, D. Stefanov, and M. Kostov, "Parametric Study on the Floor Response Spectra and the Damage
Potential of Aircraft Impact Induced Vibratory Loading," Journal of Disaster Research, vol. 5, no. 4, pp. 417-425, 2010.

[23] M. R. Sadique, M. A. Iqbal, and P. Bhargava, "Nuclear containment structure subjected to commercial and fighter aircraft crash," Nuclear Engineering and Design, vol. 260, pp. 30-46, 2013.

[24] D. Lawver, L. Nikodym, D. Tennant, and H. Levine, "Non-linear numerical modelling of aircraft impact," International Journal of Crashworthiness, vol. 6, no. 4, pp. 451-470, 2001.

[25] M. Kostov, F. O. Henkel, and A. Andonov, "Safety assessment of A92 reactor building for large commercial aircraft crash," in Proceedings of the 21th International Conference on Structural Mechanics in Reactor Technology, pp. 967-974, New Delhi, India, 2011.

[26] J. B. Liu and W. K. Zheng, "Impact load analysis on a nuclear power plant impacted by a large commercial aircraft," Journal of Vibration and Shock, vol. 33, no. 6, pp. 97-112, 2014.

[27] J. Liu, P. Han, W. Zheng, X. Lu, and L. Lin, "Numerical investigation of shield building for nuclear power plant subjected to commercial aircraft impact," Explosion and Shock Waves, vol. 36, no. 3, pp. 391-399, 2016.

[28] X. Lu, K. Lin, S. Cen, Z. Xu, and L. Lin, "Comparing different fidelity models for the impact analysis of large commercial aircrafts on a containment building," Engineering Failure Analysis, vol. 57, pp. 254-269, 2015.

[29] Boeing Website, http://www.boeing.com, 2013.

[30] Westinghouse Electric Corporation, AP1000 Design Control Document, Rev. 19, 2011.

[31] Livermore Software Technology Corporation, LS-DYNA Keyword User's Manual, Version 971, 2012.

[32] G. R. Johnson and W. H. Cook, "Fracture characteristics of three metals subjected to various strains, strain rates, temperatures and pressures," Engineering Fracture Mechanics, vol. 21, no. 1, pp. 31-48, 1985.

[33] M. R. Karim and M. S. Hoo Fatt, "Impact of the Boeing 767 Aircraft into the World Trade Center," Journal of Engineering Mechanics, vol. 131, no. 10, pp. 1066-1072, 2005.

[34] N. Jones, Structural Impact, Cambridge University Press, Cambridge, UK, 1989.

[35] W. F. Brown Jr., H. Mindlin, and C. Y. Ho, Aerospace Structural Metals Handbook, vol. 3, CINDAS/Purdue University Press, West Lafayette, Indiana, Ind, USA, 1991.

[36] Y.-T. Zhang, B.-G. Zhao, R.-G. Li, and X.-J. Du, "Monotonic and low cycle fatigue testing and research for HRB400 steel," Engineering Mechanics, vol. 33, no. 4, pp. 121-129, 2016.

[37] P. Bignon and J. Riera, "Verification of methods of analysis for soft missile impact problems," Nuclear Engineering and Design, vol. 60, no. 3, pp. 311-326, 1980.

[38] L. J. Malvar and C. A. Ross, "Review of strain rate effects for concrete in tension," ACI Materials Journal, vol. 95, no. 6, pp. 735-739, 1998.

[39] G. W. Housner, Dynamic analysis of fluids in containers subjected to acceleration, Nuclear Reactors and Earthquakes, report no. Tid 7024, US Atomic Energy Commission, Washington D. C., 1963.

[40] G. W. Housner, "The dynamic behavior of water tanks," Bulletin of Seismological Society of America, vol. 53, no. 2, pp. 381-387, 1963.

[41] Y. Yang, Seismic behavior of double-skin-composite containment structures in nuclear engineering [Ph. D. thesis], Tsinghua University, Beijing, China, 2015. 


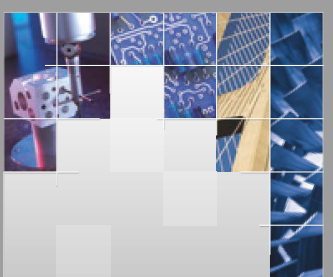

\section{Enfincering}
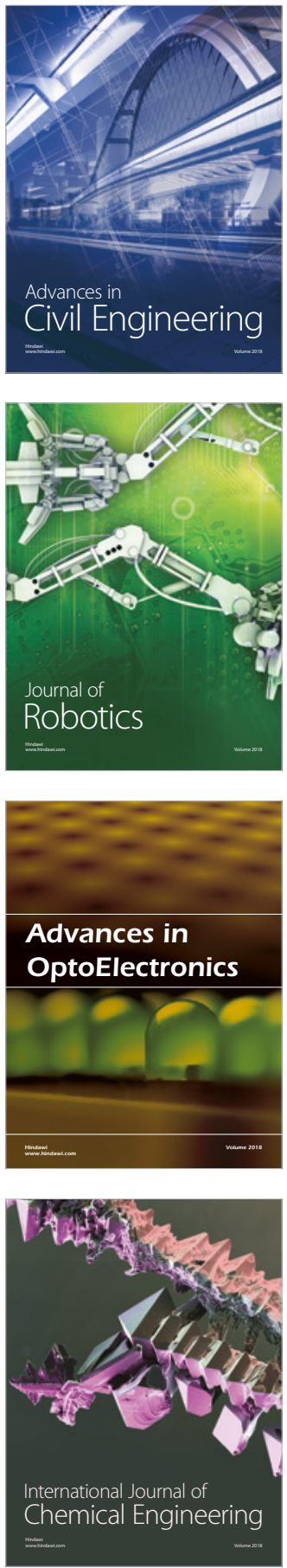

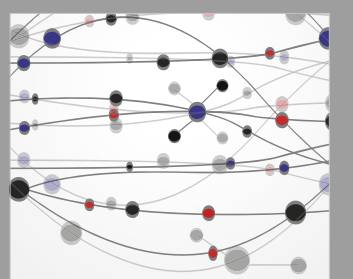

\section{Rotating \\ Machinery}

The Scientific World Journal

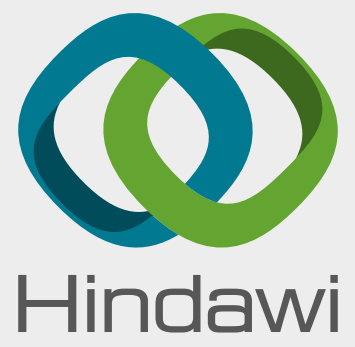

Submit your manuscripts at

www.hindawi.com
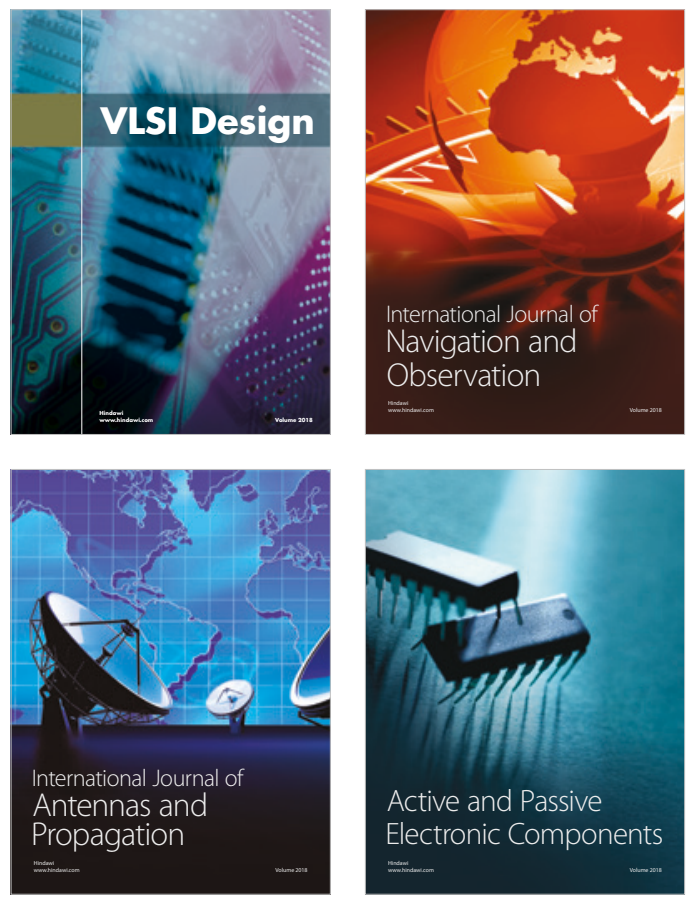
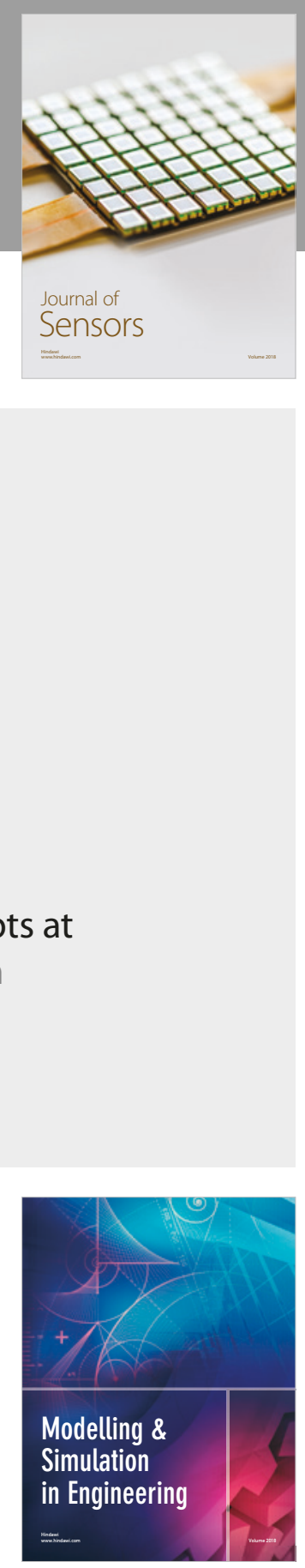

\section{Advances \\ Multimedia}
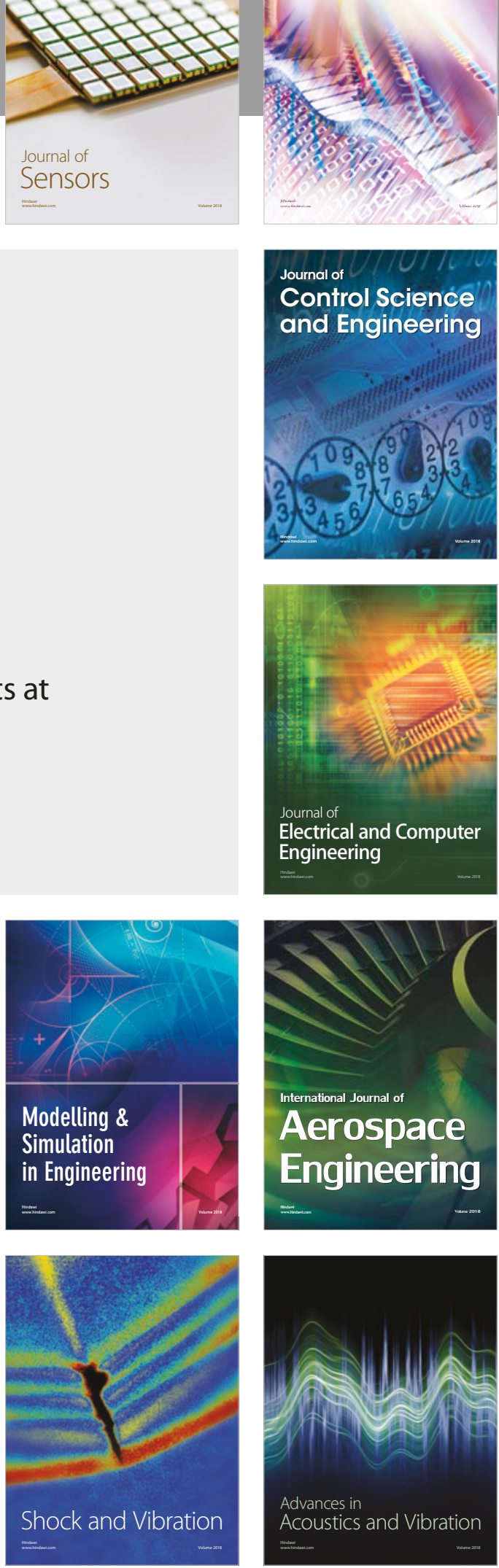